\title{
INTERACTIONS BETWEEN MINERAL SURFACES AND DISSOLVED SPECIES: FROM MONOVALENT IONS TO COMPLEX ORGANIC MOLECULES
}

\author{
UDO BECKER*†, SUBHASHIS BISWAS*, TREAVOR KENDALL**, \\ PETER RISTHAUS***, CHRISTINE V. PUTNIS****, and CARLOS M. PINA*****
}

\begin{abstract}
In order to understand the interactions of inorganic and organic species from solution with mineral surfaces, and more specifically, with the growth and dissolution behavior of minerals, we start by reviewing the most basic level of interaction. This is the influence of single monovalent ions on the growth and dissolution rate of minerals consisting of divalent ions. Monovalent ions as background electrolyte can change the morphology of growth features such as growth islands and spirals. These morphology changes can be similar to the ones caused by organic molecules and are, therefore, easily mixed up. Both $\mathrm{Na}^{+}$and $\mathrm{Cl}^{-}$promote growth and dissolution of some divalent crystals such as barite and celestite. In addition, morphology changes and the stability of polar steps on sulfates are explained using atomistic principles.

Subsequently, we will increase the level of complexity by investigating the interaction between organic molecules and mineral surfaces. As an example, we describe the influence of different organic growth inhibitors on the growth velocity of barite and use molecular simulations to identify where these organic molecules attack the surface to inhibit growth.

Nature provides a number of complex organic molecules, so-called siderophores that are secreted by plants to selectively extract Fe ions from the surrounding soil. The molecular simulations on siderophores are complemented by atomic force-distance measurements to mimic the interaction of these molecules with $\mathrm{Fe}$ and $\mathrm{Al}$ oxide surfaces. The combination of simulations and force-distance measurements allows us to evaluate initial complexation on metal oxide surfaces (which is different from metal complexation in solution), steric hindrances, the possibility to remove metal ions from oxide surfaces, and selectivity for removal of $\mathrm{Fe}^{3+}$ over $\mathrm{Al}^{3+}$.

Finally, we describe first attempts to find polypeptide sequences that may be used as precursors for biomineralization of calcite surfaces.
\end{abstract}

SELECTIVE ATTACHMENT OF MONOVALENT IONS TO POLAR STEPS ON SULFATES

Barite $\left(\mathrm{BaSO}_{4}\right)$ scale formation can be a problem by clogging pipes in technical applications and barite can also occur as a biomineral, mainly for use as a gravitational receptor, for example, in Loxedes (Mann, 2001). The scale-forming properties of barite are due to its relatively low solubility product $\left(\log \mathrm{K}_{\mathrm{sp}}=-9.96\right.$ at $20^{\circ} \mathrm{C}$, Blount, 1977) compared to other typical scale minerals such as calcite $\left(\log \mathrm{K}_{\mathrm{sp}}=-8.48\right.$ at $25^{\circ} \mathrm{C}$, Busenberg and others, 1984) and celestite $\left(\log \mathrm{K}_{\mathrm{sp}}=-6.62\right.$, Reardon and Armstrong, 1987).

Two primary strategies can be pursued to solve the scale problem: (i) Crystal growth inhibitors are used to prevent scale precipitation. The attachment of these organic molecules to active growth sites disrupts the nucleation process and hinders the continuation of growth (Bosbach and others, 2002). (ii) Complexing agents are

*Department of Geological Sciences, University of Michigan, 2534 C.C. Little Building, 1100 N. University Avenue, Ann Arbor, Michigan 48109-1063, USA

**Division of Engineering and Applied Sciences, Harvard University, Pierce Hall, 29 Oxford Street, Cambridge, Massachusetts 02138, USA

***Forschungszentrum Karlsruhe, Hermann-von-Helmholtz-Platz 1, 76344 Eggenstein-Leopoldshafen, Germany

****Institut für Mineralogie, Universität Münster, Corrensstraße 24, D-48149, Germany

*****Departamento Cristalografía y Mineralogía, Universidad Complutense, 28040 Madrid, Spain

†Corresponding author: E-mail address: ubecker@umich.edu 
applied to dissolve barite precipitates. The latter has the disadvantage that large amounts of chelators are necessary because one chelator molecule is consumed for each dissolved cation (Coveney and others, 2000).

In order to understand barite scale formation and to improve scale treatment technologies, a sound understanding of the complex precipitation and dissolution processes is required. Although much work has been dedicated to study these processes from a macroscopic point of view (Dove and Czank, 1995), microscopic mechanisms such as two-dimensional nucleation, spiral growth, and etch pit formation have to be studied at a molecular level. Atomic Force Microscopy (AFM) can be used to characterize individual growth and dissolution mechanisms in situ. Details on barite growth and dissolution have been reported in numerous AFM studies (Archibald and others, 1997; Pina and others, 1998a, 1998b; Bosbach, 2002). Special attention has been paid to the effect of organic growth inhibitors (van der Leeden and others, 1995; Bosbach and others, 1998), organic chelators (Putnis and others, 1995), pH (Dunn and Yen, 1999), and temperature (Monnin and Galinier, 1988; Higgins and others, 1998). However, the influence of the ionic strength, specifically the role of monovalent cations temporarily attaching to surface steps, on the barite scale formation has been neglected in microscopic studies. However, the role of background electrolytes can be important because in offshore exploration, the injected seawater has high ionic strength $(I=0.7)$. Only one study involving calcite has attempted this: Shiraki and others (2000) have determined the dissolution kinetics in $0.1 \mathrm{M} \mathrm{NaCl}$ solution in AFM experiments. Macroscopic experiments indicate that barite precipitation (He and others, 1995) and dissolution kinetics are affected by the presence of background electrolytes (Christy and Putnis, 1993). Here, we review AFM observations on the influence of ionic strength on growth and dissolution of barite with some comparative experiments with celestite (Becker and others, 2002). Furthermore, certain microtopographic features such as the morphology of etch pits and molecular islands can be clearly associated with the presence of specific background electrolytes. In highly saline solutions, we obtain very similar etch pit morphologies to those which have previously been attributed to specific interactions between organic molecules and certain sites on a mineral surface (Wang and others, 1999a, 1999b, 2000). In other words, it is crucial to understand possible interactions of single-atom ions with mineral surfaces, in particular their influence on growth rates and morphologies, before more complex organic-mineral interactions such as biomineralization are considered.

In recent years, an increasing number of molecular simulation studies were performed on the influence of foreign cations and inhibitor molecules on the growth and dissolution of mineral surfaces, particularly on carbonate (Parker and others, 1993; Nygren and others, 1998; de Leeuw and others, 1999; Gerbaud and others, 2000; Cooper and de Leeuw, 2002; de Leeuw and Cooper, 2004) and sulfate surfaces (Allan and others, 1993; Rohl and others, 1996; de Leeuw and Parker, 1997; Redfern and Parker, 1998; Risthaus and others, 2001; Becker and others, 2002). It was shown that a precise description of hydration energies in solution and at the surface is crucial for the analysis of the subtle but significant differences of the adsorption thermodynamics of different ions on specific surface sites (Sayle and others, 2000). The net adsorption energy to a specific surface site can be described in the following way (eq 1):

$$
E(\text { ads. in water })=E(\text { ads. in vacuo })-X \times E(\text { hyd. in bulk water })
$$

where $E$ (ads. in water) is the net adsorption energy in water, E(ads. in vacuo) is the adsorption energy in vacuum, $E$ (hyd. in bulk water) is the hydration energy in bulk water (which tends to prevent adsorption), and $X$ (with $0<X<1$ ) accounts for the fact that the adsorbed species is still partially hydrated when adsorbed. We calculated the factor $X$ from molecular dynamics simulations by using a setup with the adsorbate on the 
surface and four layers of water covering the surface. Each of these relatively large energy contributions needs to be evaluated precisely to obtain a sensible value for the relatively small net adsorption energy that remains. It can be a formidable task to derive all these energy contributions for all relevant surface sites. This is because the energy contributions depend on type of mineral, its face exposed, and whether the adsorption site is on a terrace, a step, or a kink. In addition, adsorption energies in vacuo and hydration depend on the adsorbate. However, this knowledge will be necessary to predict thermodynamic equilibria of the adsorption of different cations and to judge if growth inhibitor molecules will be overgrown or redissolved (Nygren and others, 1998). We used a combination of AFM results from experiments in a fluid cell and molecular simulations to identify the rate-limiting steps for growth and dissolution of barite under different solution conditions. Subsequently, it is possible to describe the role of adsorption in a hydrous environment to explain the mechanisms and reaction pathways of crystal growth and dissolution depending on the composition of a solution in contact with a specific mineral surface.

\section{Experimental and Theoretical Methods to Determine the Adsorption of Monovalent Ions on Barite Steps}

The experimental and theoretical methods used here are described in more detail elsewhere (Pina and others, 1998a, 1998b, 2004; Risthaus and others, 2001; Becker and others, 2002). In brief, crystal growth and dissolution was measured as step advancement and retreat velocities in AFM fluid cell experiments on (001) barite and (001) celestite surfaces as a function of different supersaturation values $S$ (with $S=I A P / K_{s p}$, $I A P$ is the ion activity product in solution $\left.=\mathrm{a}_{\text {cation }} \times \mathrm{a}_{\text {sulfate }}\right)$ and background electrolyte concentrations.

Calculations of sulfate surfaces and on the interaction between background electrolyte ions and specific sulfate surface features were performed using empirical potential force field models based on the sulfate potentials developed by Allan and others (1993). For all computations of step energies and adsorption energies, we applied two-dimensional periodic boundary conditions parallel to the surface. For computations involving surface relaxation, the uppermost two molecular layers (out of four) were allowed to relax. This thickness is sufficient because relaxation does not progress far into the bulk of what we tested using thickness-dependent surface relaxation calculations.

We define step energies as the energies that a surface step is energetically less favorable (per unit length of step; see also Becker and Gasharova, 2001) than the same number of atoms on a flat terrace. Step energies are calculated by comparing a relaxed step structure with a relaxed flat surface ("relaxed" case) or an unrelaxed step with a bulk terminated surface ("unrelaxed" case).

Bulk hydration energies of ions dissolved in solution were taken from experimental values from Rashin and Honig (1985) and references therein. Partial hydration energies of adsorbed surface species were calculated by performing molecular dynamics simulations with four water layers on the surface with and without the adsorbed species (see also Becker and others, 1998). Water potentials were tested to be in good agreement (less than 5\% error) with the experimental hydration energies described in Rashin and Honig (1985) by applying the droplet method.

\section{AFM Results of Monolayer Step Growth in the Presence of Background Electrolytes}

The most dominant growth mechanism on barite and celestite surfaces is the attachment of ions from solution onto kink sites leading to the advancement of molecular steps. The growth kinetics of such steps was studied at various background electrolyte concentrations. However, in order to study this effect quantitatively, step growth rates were measured on barite (001) surfaces at constant supersaturation with 
increasing ionic strength. Due to the decrease of the mean activity coefficients of aqueous $\mathrm{Ba}^{2+}$ and $\mathrm{SO}_{4}{ }^{2-}$, the concentration of $\mathrm{Ba}^{2+}$ and $\mathrm{SO}_{4}{ }^{2-}$ in solution had to be increased with increasing salinity in order to obtain constant IAPs for barite and celestite, respectively. In addition, the formation of $\mathrm{NaSO}_{4}{ }^{-}$and $\mathrm{BaSO}_{4}$ species in solution further reduces the free $\mathrm{SO}_{4}{ }^{2-}$ activity. Consequently, $\mathrm{Ba}^{2+}$ and $\mathrm{SO}_{4}{ }^{2-}$ concentrations have to be increased non-stoichiometrically with increasing $\mathrm{NaCl}$ background electrolyte concentration.

After injecting a moderately supersaturated $\mathrm{BaSO}_{4}$ solution $(S=19.6)$ with low background electrolyte concentration (ionic strength $=0.003$ ) into the AFM fluid cell, two-dimensional islands with a height of one molecular $\mathrm{BaSO}_{4}$ layer form on a barite (001) surface as shown in figure 1A. Their lateral spreading results in a distinct circular sector-shaped morphology, which reflects the relative growth rates in different crystallographic directions. The morphology is controlled by straight step edges parallel to [120] and [1 $\overline{2} 0]$ (since both are symmetry equivalent, they are often referred to as $\tau$ ) and a curved step edge between them. The orientation of these islands alternates in consecutive molecular layers due to the $2_{1}$ screw axis parallel to [001]. Step edges parallel to $\tau$ form relatively stable periodic bond chains with a low kink site density. In contrast, the curved step edges that advance in the fast growth direction have a high kink site density. Therefore, the curved step edges are the most reactive parts of the barite (001) surface where step growth preferentially occurs. The growth velocity of these islands is highly anisotropic. Growth normal to the curved step edges is approximately 10 times faster than growth normal to the straight edges.

Figures 1A, B, and figure 2 indicate that the monolayer step velocity increases with increasing $\mathrm{NaCl}$ concentration at constant supersaturation. However, monolayer step growth is not increased by the same factor for all crystallographic directions. Therefore, the island morphology and aspect ratio change depending on the $\mathrm{Na}^{+}$and $\mathrm{Cl}^{-}$ concentration. Molecular islands are more elongated in the [010] direction and the angle between the straight edges (originally [120] and [1 $\overline{2} 0]$, fig. 1B) of the sectorshaped islands becomes more obtuse.

The formation of growth spirals is also affected by the relative changes in monolayer step edge reactivity with increasing concentration of monovalent ions in solution. The contribution of spiral growth on the barite (001) surface to the overall volume growth is limited by the advancement of the slowest step because spirals are bounded by these steps (Pina and others, 1998a). On barite (001) surfaces, these bounding steps are parallel to $\tau$ at low ionic strength (fig. 1C). This leads to spiral growth hillocks with relatively little lateral growth compared to two-dimensional islands. Also in the case of spiral growth, growth rates in different crystallographic directions change with increasing $\mathrm{NaCl}$ concentration resulting in more elongated growth spirals (fig. 1D).

Similar observations have been obtained on the (001) surface of isostructural celestite (Risthaus and others, 2001; Becker and others, 2002).

Dissolution: etch pit formation and monolayer step retreat.-Similar solvent effects on monolayer step reactivity can also be obtained from in situ dissolution experiments. After exposing a freshly cleaved barite (001) surface to deionized water, relatively few etch pits form (up to $0.1-0.2$ pits $/ \mu \mathrm{m}^{2}$ in 15 min., fig. 1E). Typically, the etch pit morphology is defined by monolayer step edges parallel to $\tau$ and to [010]. In consecutive molecular layers, they have opposite orientations, due to the $2_{1}$ screw axis normal to the (001) surface. During etch pit formation, dissolution occurs via the retreat of monolayer steps. The lateral spreading rate of etch pits in pure deionized water is $0.08 \pm 0.02 \mathrm{~nm} / \mathrm{s}$ parallel to [010] and $0.03 \pm 0.01 \mathrm{~nm} / \mathrm{s}$ parallel to [100]. In high ionic strength solution (up to $1.0 \mathrm{M} \mathrm{NaCl}$ ), the step reactivity and the etch pit morphology changes. The lateral spreading rate increases to $1.27 \pm 0.03 \mathrm{~nm} / \mathrm{s}$ parallel 

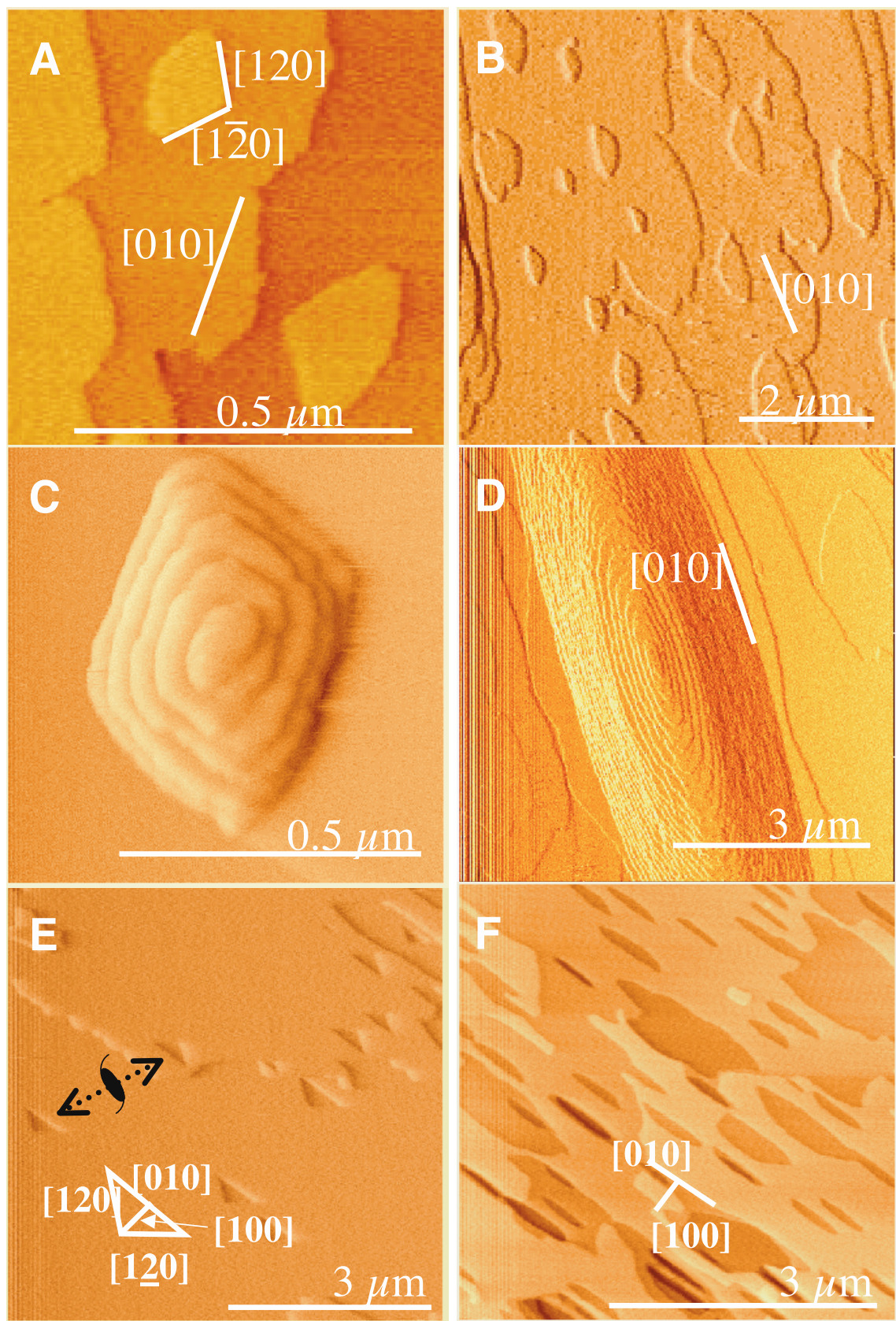

Fig. 1. (A) Two-dimensional nuclei are formed on the (001) surface in a supersaturated pure $\mathrm{BaSO}_{4}$ solution. Note the opposite orientation of the sector-shaped islands in consecutive layers. (B) For the same supersaturation, the islands become more elongated with increasing $\mathrm{NaCl}$ content (increasing ionic strength, 0.75 here). (C) Due to the growth anisotropy in consecutive $\mathrm{BaSO}_{4}$ layers, the shape and the lateral spreading of the growth spiral is controlled by the slowest growing molecular step. (D) The change in step velocities in different crystallographic directions is also reflected by a different morphology of growth spirals. (E) AFM image of dissolution of a barite (001) surface in pure water. Triangular etch pits with a depth of half a unit cell (one monolayer) are formed on the surface. The step edges are parallel to [010], [120], and [120]. Due to the $2_{1}$ screw axis, triangular etch pits in consecutive atomic layers have opposite orientations. (F) In a 1.0 M NaCl solution, the etch pits become elongated with curved step edges more or less parallel to [010] (modified from Becker and others, 2002). 


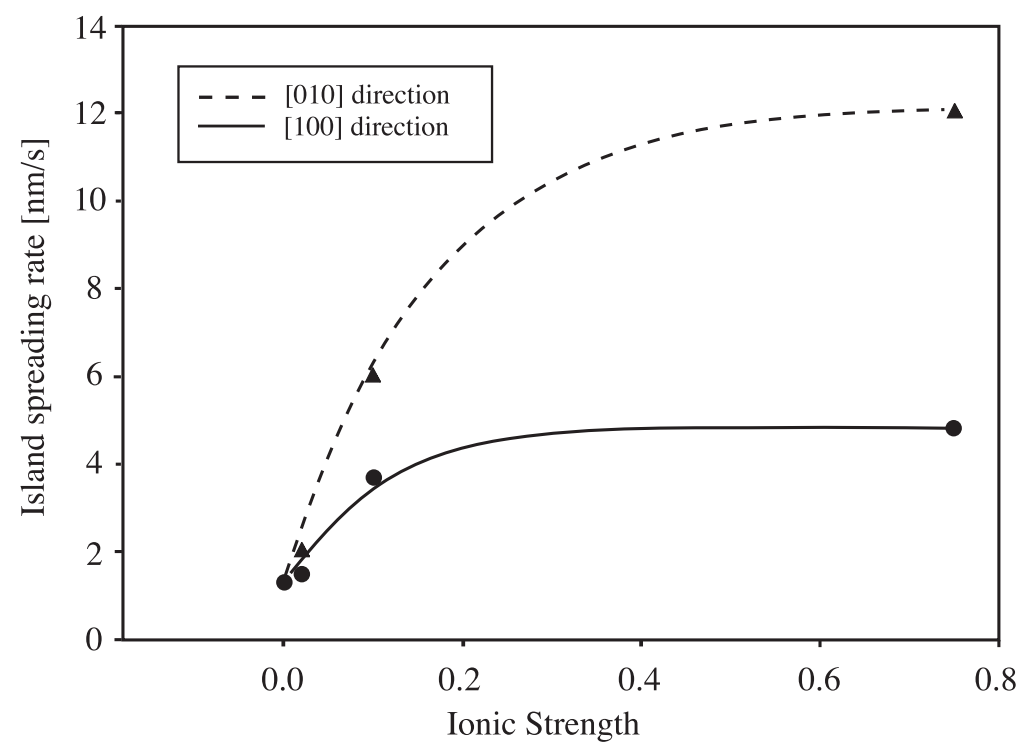

Fig. 2. Island spreading velocity vs. ionic strength with constant supersaturation ratio.

to [010] and $0.31 \pm 0.03 \mathrm{~nm} / \mathrm{s}$ parallel to [100]. Consequently, the etch pits are more elongated parallel to [010] and bounded by curved monolayer steps (fig. 1F). Also, the initial number of etch pits is $1.4-2.2$ pits $/ \mu \mathrm{m}^{2}$ after $5 \mathrm{~min}$., about an order of magnitude higher than in pure water.

\section{Computational Description of Interactions between Monovalent Ions in Solution and Divalent Mineral Surfaces}

In order to interpret the influence of $\mathrm{Na}^{+}$and $\mathrm{Cl}^{-}$in solution on the morphologies and rates of growth and dissolution of sulfate surfaces, one has to analyze the changes in the bulk solution, in the near surface region, and direct interactions between the background electrolyte ions and the surface. Most insight can be gained from molecular simulations to resolve the mechanisms of the latter processes.

Dissolution.- When we try to develop a picture of these etch pits from a molecular point of view of a pure $\mathrm{BaSO}_{4}$ (001) surface, we obtain an etch pit as shown in figure 3 . Figure 3 shows an etch pit that is bounded by step directions as in the experimental AFM image shown in figure 1E. The $\tau$ step directions are bounded by periodic bond chains (alternating $\mathrm{Ba}^{2+}$ and $\mathrm{SO}_{4}{ }^{2-}$ ions) with no dipole moment perpendicular to the step, both first indications for a relative stable step (step energy $0.31 \mathrm{eV} / \AA$ ). In contrast, the third step direction $\| \vec{b}$ would be either bounded by $\mathrm{SO}_{4}{ }^{2-}$ or $\mathrm{Ba}^{2+}$ ions, resulting in a dipole moment perpendicular to the step and an unfavorable step energy $(1.33 \mathrm{eV} / \AA)$. In addition to the difference in step energies, a polar step is more likely to be attacked by water molecules from solution due to its local charge. One way to solve the problem of a local dipole moment is to "construct" a jagged edge that would represent an etch pit as in figure 4 . Figure 4 can be understood as if half of the ions along the previously polar step are removed, which removes the dipole moment perpendicular to the step. Therefore, the step energy (in vacuum) decreases to 0.63 $\mathrm{eV} / \AA$ in the unrelaxed case and $0.50 \mathrm{eV} / \AA$ for the case where the step atoms are allowed to relax. If we stay in our framework of an etch pit that would just consist of a $\mathrm{BaSO}_{4}$ surface, such a step has a high density of kink sites (1.8 kink sites/nm) which makes it more likely for hydration and, thus, for dissolution to occur (fig. 4). 


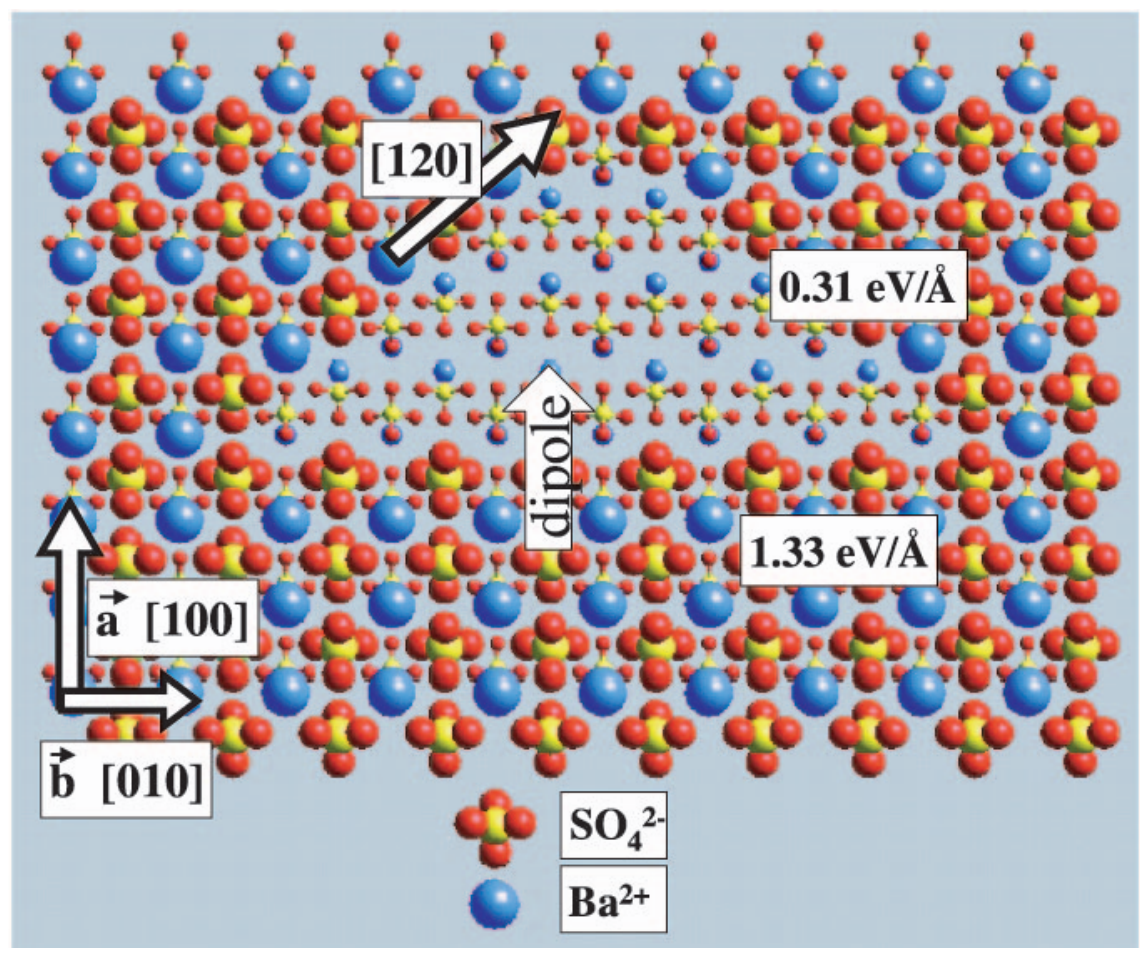

Fig. 3. Model of an etch pit on the barite (001) surface. While there are alternating $\mathrm{Ba}^{2+}$ and $\mathrm{SO}_{4}{ }^{2-}$ ions along the $\tau$ directions, which causes electrostatically neutral and fairly stable steps (step energy $0.31 \mathrm{eV} / \AA$ ), straight steps along [010] consist of either $\mathrm{Ba}^{2+}$ or $\mathrm{SO}_{4}{ }^{2-}$ (shown in the figure) ions. Thus, there is a strongly positively or negatively charged step (in this case negatively charged). This causes a dipole moment perpendicular to the step, which is an indication for unstable step termination (atoms in the uppermost surface sublayer are represented by larger balls than in layers underneath). The resulting step energy is

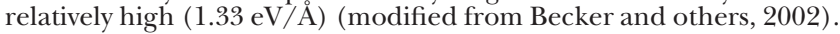

The next question is how the situation changes once the solution in contact with the etch pit contains monovalent background electrolyte ions such as $\mathrm{Na}^{+}$and $\mathrm{Cl}^{-}$ions. The case for an idealized and temporary (see below) $\mathrm{Na}^{+}$termination is shown in figure 5. Each $\mathrm{Ba}^{2+}$ is replaced by two $\mathrm{Na}^{+}$ions and the result is a dipole-free and kink-free step. Interestingly, this step is less stable in vacuum (by $0.24 \mathrm{eV} / \AA$ ) due to the $\mathrm{Na}-\mathrm{Na}$ repulsion and the stronger affinity of $\mathrm{Ba}^{2+}$ for $\mathrm{SO}_{4}{ }^{2-}$ than of $\mathrm{Na}^{+}$. However, since the twofold charge causes the hydration energy of $\mathrm{Ba}^{2+}$ in solution to be on the order of three times higher than the one of $\mathrm{Na}^{+}(13.64 \mathrm{eV}$ vs. $4.27 \mathrm{eV}$, Rashin and Honig, 1985), the loss in hydration energy is more than compensated and the net gain is $0.17 \mathrm{eV} / \AA$. Thus, the final step energy of $0.33 \mathrm{eV} / \AA$ is on the order of the step energy of the $\tau$ steps $(0.31 \mathrm{eV} / \AA)$. The energy budget of adsorption of $\mathrm{Na}^{+}$or $\mathrm{Cl}^{-}$to the PBC-like $\tau$ step is much less favorable, such that we can conclude that adsorption of monovalent background ions takes place predominantly on steps that would be polar without the background electrolytes (fig. 5). Thus, the increased relative stability of steps parallel [010] with respect to $\tau$ is due to the formation of PBC-like $-\mathrm{Na}_{-} \mathrm{SO}_{4}-\mathrm{Na}$ $\mathrm{SO}_{4^{-}}$or -Cl-Ba-Cl-Ba- chains along the step, which are less polar (and hence more stable) than terraces bounded by either $\mathrm{SO}_{4}{ }^{2-}$ or $\mathrm{Ba}^{2+}$. It has to be noted that the described adsorption pattern is not a static termination of the step but rather a temporary picture. The decoration of a polar step with $\mathrm{Na}^{+}$will always be incomplete 


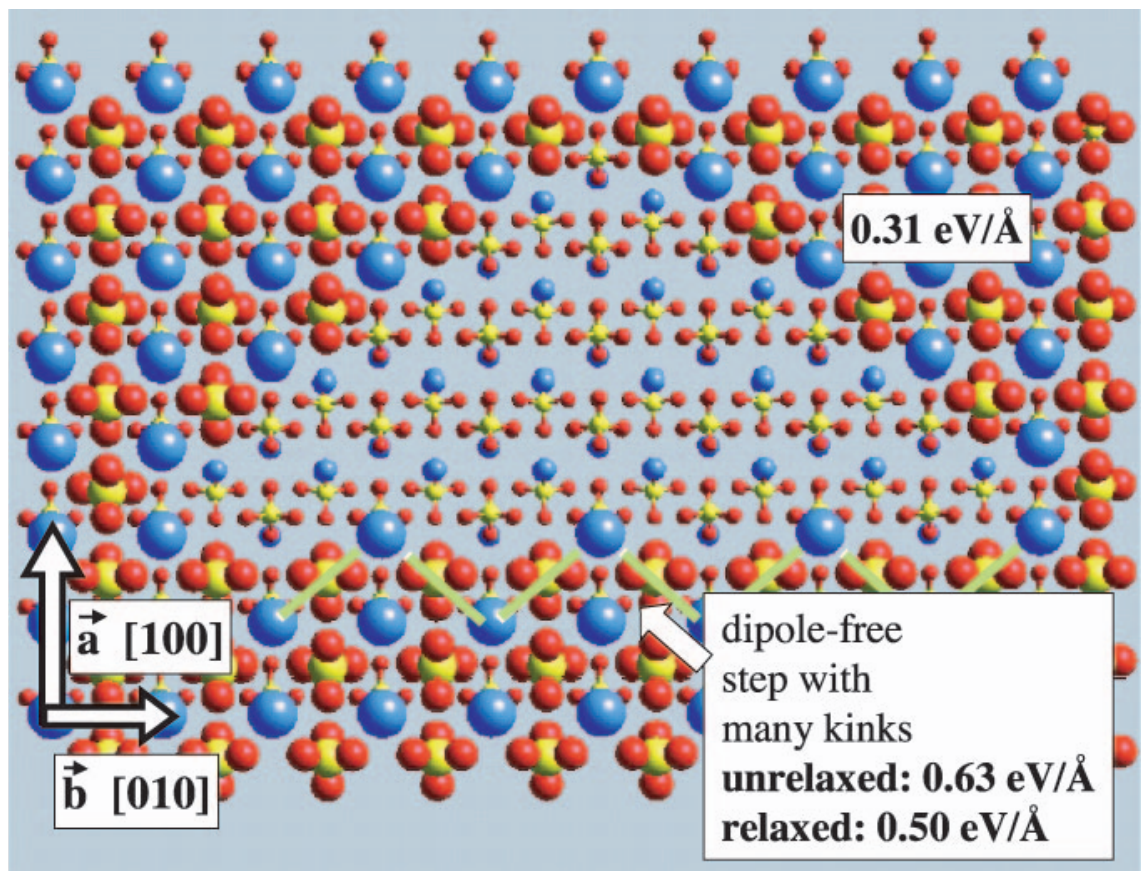

Fig. 4. By removing every other $\mathrm{SO}_{4}{ }^{2-}\left(\right.$ or $\left.\mathrm{Ba}^{2+}\right)$ ion from such a polar step, the dipole moment perpendicular to the step vanishes, and the step energy is reduced (from $1.33 \mathrm{eV} / \mathrm{A}$ for the polar case) to $0.63 \mathrm{eV} / \AA$ in the unrelaxed case and $0.50 \mathrm{eV} / \AA$ in the relaxed case. However, this setup creates a large number of kink sites along the [010] step direction which makes this step still significantly less favorable than steps $\| \tau$ (step energy $0.31 \mathrm{eV} / \AA$ ) in pure water. Therefore, these steps are less stable in solutions with low ionic strength (modified from Becker and others, 2002).

such that dissolution progresses for undersaturated $\mathrm{BaSO}_{4}$ solutions concurrent with the formation of thermodynamic equilibrium conditions between $\mathrm{Na}^{+}$and $\mathrm{Ba}^{2+}$ on step sites or between $\mathrm{Cl}^{-}$and $\mathrm{SO}_{4}{ }^{2-}$. In addition, even though the adsorption of $\mathrm{Na}^{+}$ $\left(\mathrm{Cl}^{-}\right)$to polar steps is more favorable than the adsorption of $\mathrm{Ba}^{2+}\left(\mathrm{SO}_{4}{ }^{2-}\right)$, the divalent ions are energetically downhill on lattice sites of flat terraces or in the bulk.

The mechanism of decorating polar steps with background electrolyte ions is an explanation for the different morphologies of etch pits in solutions with and without background electrolytes. The next question to be answered is: What is the influence of background ions on the dissolution rate of sulfate surfaces. We start our considerations with an "etch pit nucleus" that is bounded by steps that are parallel to PBCs (fig. 6A). In distilled water, the first ion to be dissolved would be most likely a $\mathrm{Ba}^{2+}$ ion (fig. $6 \mathrm{~B}$ ) because the binding energies of $\mathrm{Ba}^{2+}$ and $\mathrm{SO}_{4}{ }^{2-}$ to the lattice are comparable but the hydration energy of $\mathrm{Ba}^{2+}$ in water $(13.64 \mathrm{eV})$ is significantly higher than the one for $\mathrm{SO}_{4}{ }^{2-}(9.73 \mathrm{eV}$, Becker and others, 2002). This process leaves behind a double kink site with a local formal charge of -2 . This intermediate state is energetically uphill and, therefore, the rate-limiting factor for the initiation of further dissolution. The solvation of the cation is followed by the dissolution of a neighboring sulfate ion which is a fast step compared to the initial dissolution (fig. 6C). In solutions with high concentrations of monovalent ions, the unfavorable state in figure $6 \mathrm{~B}$ is avoided by substituting the $\mathrm{Ba}^{2+}$ ion by a $\mathrm{Na}^{+}$ion, leaving no kink and a local formal charge of just -1 (fig. 6D). Consecutively, a sulfate ion can be replaced by a chloride ion (fig. 6E) and the result is a neutral substitution with relatively low activation energies of any of the 


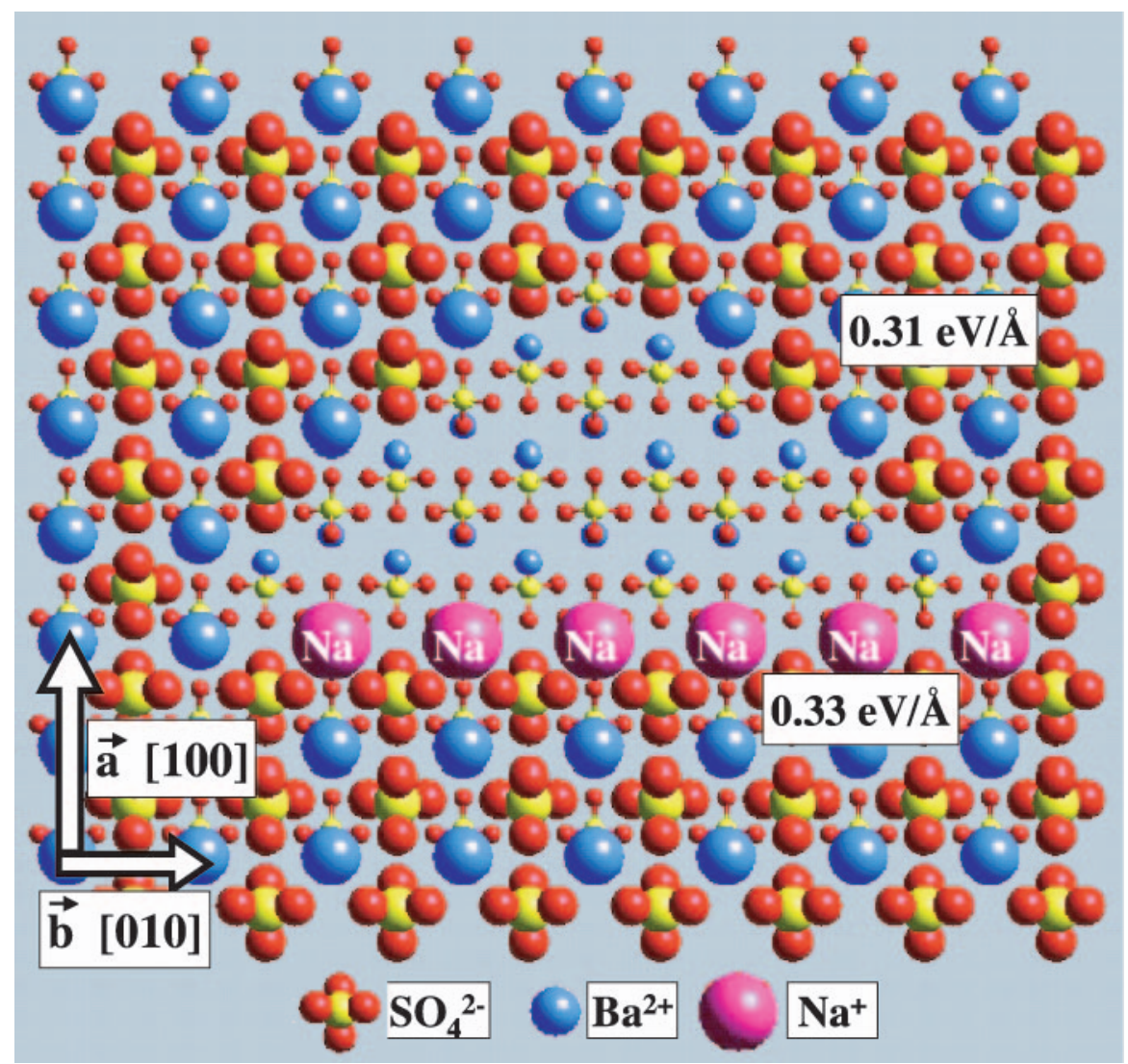

Fig. 5. More favorable is a step termination with a row of $\mathrm{Na}^{+}$ions occupying every lattice site along the step compared to $\mathrm{Ba}^{2+}$ occupying every other site. The energy budget of such a theoretical substitution is derived in the text. Similarly, one molecular row further down in the [100] direction, there would be a -Cl-Ba-Cl-Ba-Cl-chain. With this setup, all three steps have comparable step energies, which nicely explains the shape of triangular etch pits found in the experimental images (modified from Becker and others, 2002).

intermediate dissolution steps. This process contributes to the increased dissolution rates in solutions with a high ionic strength, in addition to the lowered interfacial free energy (strictly speaking, this mechanism also contributes to the interfacial free energy) in the near surface region and the reduced activity coefficient in the bulk solution. This theoretical consideration of the temporary substitution of a divalent ion from the structure by a monovalent ion from solution suggests that growth and dissolution rates are strongly influenced by the valency of the background electrolyte ions. Furthermore, the identity of the background electrolyte ions can control the "bottlenecks" of growth and dissolution by lowering the ion exchange energy (for example, $\left.\mathrm{Ba}^{2+} \leftrightarrow \mathrm{Na}^{+}, \mathrm{SO}_{4}{ }^{2-} \leftrightarrow \mathrm{Cl}^{-}\right)$. Further experimental studies will have to verify these findings.

Growth.-When describing the important features of crystal growth, the key issue is to find the rate-limiting steps, that is the "bottle necks" through which crystal growth has to go before more favorable adsorption events can follow. Once this rate-limiting factor is found the next step is to find the most energetically favorable reaction path. During crystal growth of barite, sector-shaped islands are formed with very anisotropic 


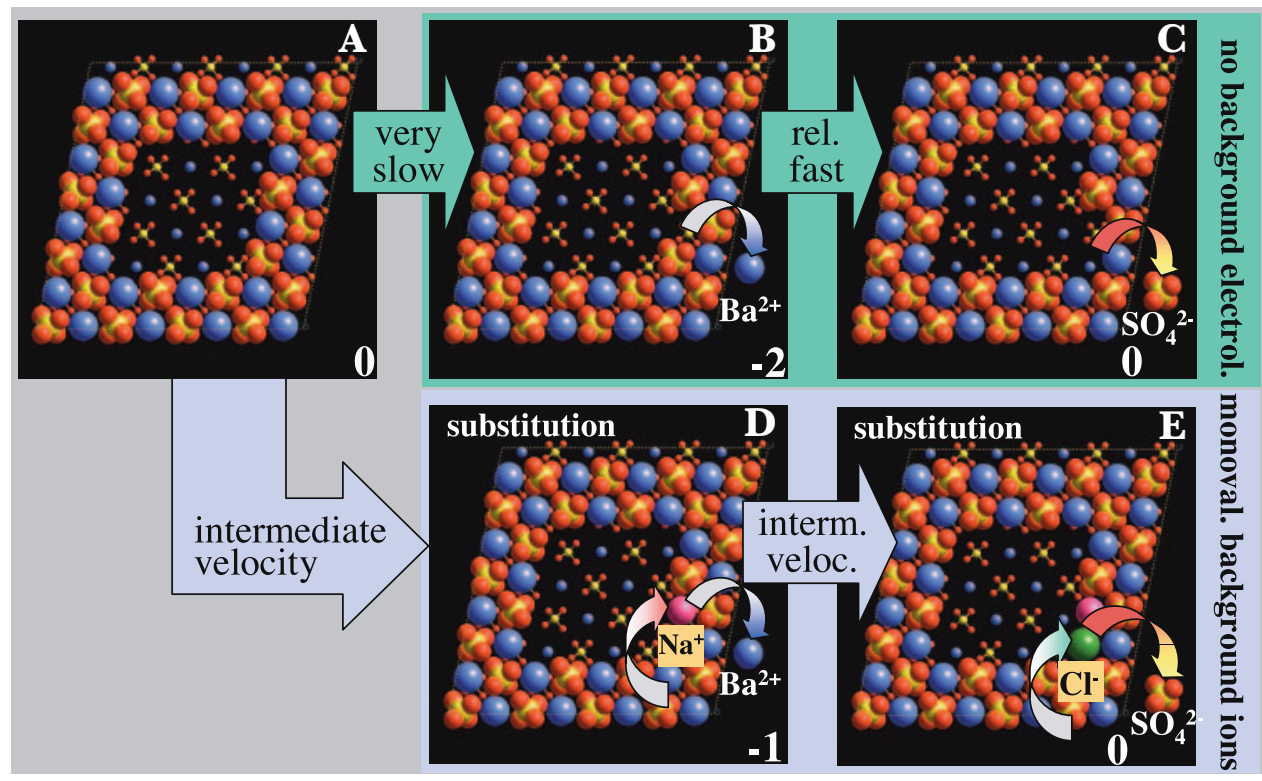

Fig. 6. Schematic of barite (001) surface dissolution in pure water and in the presence of a monovalent background electrolyte solution. (A) Structure of a (theoretical) etch pit "nucleus" bound by PBCs $\| \tau$. (B) The dissolution of $\mathrm{Ba}^{2+}$ and thus the formation of a double kink is unfavorable, because a twofold negative site is created. This is the rate-limiting step of dissolution. (C) The consecutive step of dissolving a neighboring sulfate ion is exothermic and not rate limiting. (D) The initial dissolution step can be mediated by the substitution of $\mathrm{Ba}^{2+}$ by $\mathrm{Na}^{+}$, which makes dissolution less rate limiting than scenario (B). Even though the following substitution of a sulfate by a chloride ion is less favorable than the sulfate dissolution in $(\mathrm{C})$, it is also energetically downhill and, thus, not rate limiting (modified from Becker and others, 2002).

growth velocities (fig. 7A). By combining the findings from AFM experiments and molecular simulations, it was found that the rate-limiting step was the creation of a new growth row (fig. 7B). These rows then continue growing towards point $\mathbf{C}$ and result in an average fast growth vector. Since adsorption of ions from solution to positions on the other side of the PBCs is less favorable, growth in the opposite direction is much slower.

Now, we have to answer the question if monovalent ions from solution can lower the energy to create a new growth row. Apart from changes in the diffusion layer, the task is to compare the energetics of this first adsorption event. Let us first consider the adsorption of $\mathrm{a} \mathrm{Ba}^{2+}$ cation to a potential starting island as shown in figure 8A. The gain in adsorption energy in vacuum to this specific site is $10.81 \mathrm{eV}$ (for better graphical representation, fig. 8 shows the unrelaxed positions of the atoms in the island and the relaxed positions of the adsorbed $\mathrm{Ba}^{2+}$ and $\mathrm{Na}^{+}$ions). Because the newly adsorbed $\mathrm{Ba}^{2+}$ ion is still partly hydrated (we have calculated the remaining hydration energy on this particular site to be close to $20 \%$ of the hydration energy in bulk water) the loss in hydration energy is 80 percent of the hydration energy of the dissolved species. Thus, the total adsorption energy in water is $-10.81 \mathrm{eV}-(0.8 \times 13.64$ $\mathrm{eV})=-0.10 \mathrm{eV}$. Note that these calculations have an error of at least \pm 0.1 to $0.2 \mathrm{eV}$. Therefore, in this case, one cannot be sure if this adsorption step is exothermic or endothermic. The respective calculation for the $\mathrm{Na}^{+}$adsorption energy is $-4.94 \mathrm{eV}$ $-(0.8 \times 4.27 \mathrm{eV})=-1.52 \mathrm{eV}$. Thus the weaker adsorption of $\mathrm{Na}^{+}$in vacuum is more than compensated by the much smaller loss in hydration energy. This is mainly caused by the fact that adsorption is roughly proportional to the charge of the ion but hydration 

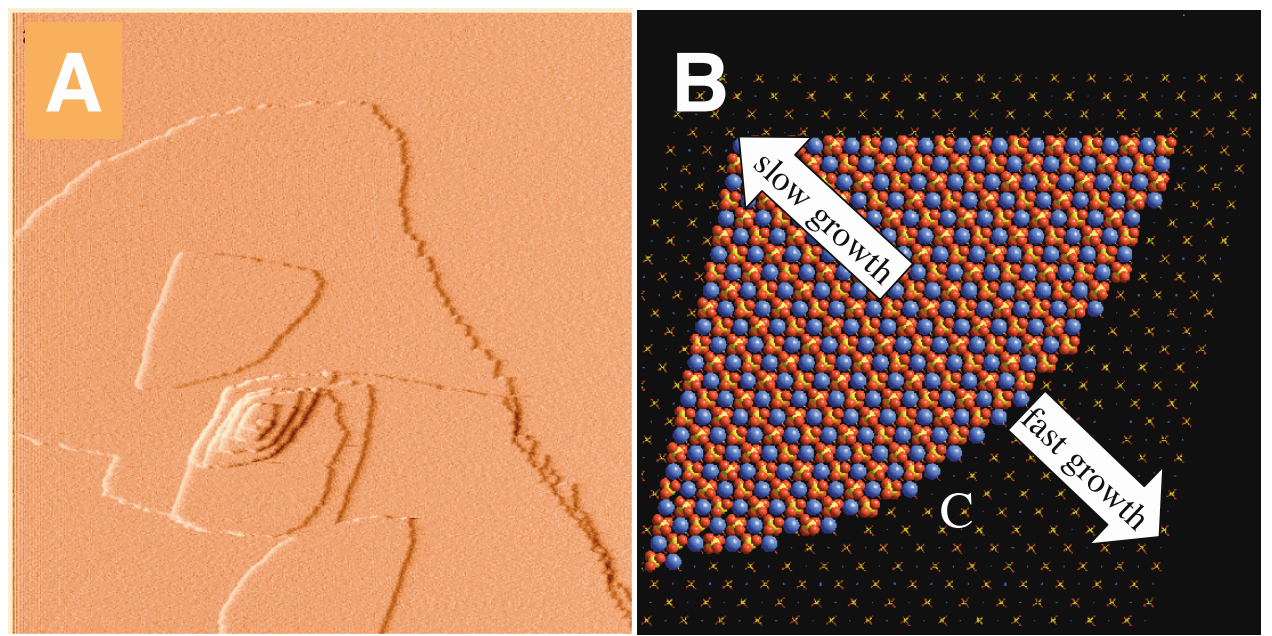

Fig. 7. (A) Sector-shaped islands during growth on barite (001). (B) Molecular simulation model of the rate-limiting steps during formation of a sector-shaped island shown in (A) (modified from Becker and others, 2002). For an animation of a barite island growth, see http://www.geo.lsa.umich.edu/ compmin/Research/Sulfates/purebarite.html.

approximately proportional to the square of the charge (for equal ionic radii). Thus, we can conclude that $\mathrm{Na}^{+}$ions in solution can create a new row by adsorbing a "trial ion" to the preexisting island. Even though the adsorption of the next sulfate ion in such a row is less favorable in the $\mathrm{Na}^{+}$case than for the $\mathrm{Ba}^{2+}$ case, in both cases, the continuation of growth is energetically downhill and thus no growth-limiting factor. It is interesting to note that the continuous growth is in favor of $\mathrm{Ba}^{2+}$ incorporation rather than $\mathrm{Na}^{+}$incorporation and also, the substitution of the "trial adsorption site" with $\mathrm{Na}^{+}$by $\mathrm{Ba}^{2+}$ is energetically downhill. This can be explained in the following way: adsorption in vacuum is stronger than the first adsorption to the preexisting island for both cases $\mathrm{Na}^{+}(-8.39 \mathrm{eV})$ and $\mathrm{Ba}^{2+}(-16.83 \mathrm{eV})$ because an additional bond is formed to the neighboring sulfate ion. The gain in hydration energy during dissolution is also greater because at such a corner site, the respective ion is less exposed to the solution such that only about 15 percent of the bulk water hydration is left. Therefore, we can calculate the energy balance for the substitution of $\mathrm{Na}^{+}$by $\mathrm{Ba}^{2+}$ in figure $8 \mathrm{C}, \mathrm{D}$ to be:

$$
\begin{aligned}
\Delta \mathrm{E}_{\text {subs }}=-\left[-8.39_{\text {Na_ads }}+0.85 \times 4.27_{\text {Na_hyd }}\right] \mathrm{eV} & \\
& +\left[-16.83_{\text {Ba_ads }}+0.85 \times 13.64_{\text {Ba_hyd }}\right] \mathrm{eV}=-0.48 \mathrm{eV}
\end{aligned}
$$

Therefore, $\mathrm{Na}^{+}$serves the purpose of creating a temporary adsorption site that helps to form a new step and is later substituted. This process could be described as a healing effect of the crystal during continuous growth. This finding agrees with the fact that a $\mathrm{Na}^{+}$ion does not fit well into the barite structure, for reasons of both size and charge neutrality. Bulk crystallographic results indicate that $\mathrm{Na}^{+}$or $\mathrm{Cl}^{-}$ions will finally be substituted by $\mathrm{Ba}^{2+}$ or $\mathrm{SO}_{4}{ }^{2-}$ to complete the barite structure, although $\mathrm{Na}^{+}$or $\mathrm{Cl}^{-}$ions in growing rows serve to create the initial kink site.

In addition to the atomic-scale description of changes in step energies and the energies of rate-controlling sites, background electrolytes influence the thermodynamic properties of the bulk solution and of the near-surface region at the mineralwater interface. These changes and their influence on growth and dissolution rates are described in Risthaus and others (2001) and Becker and others (2002). 


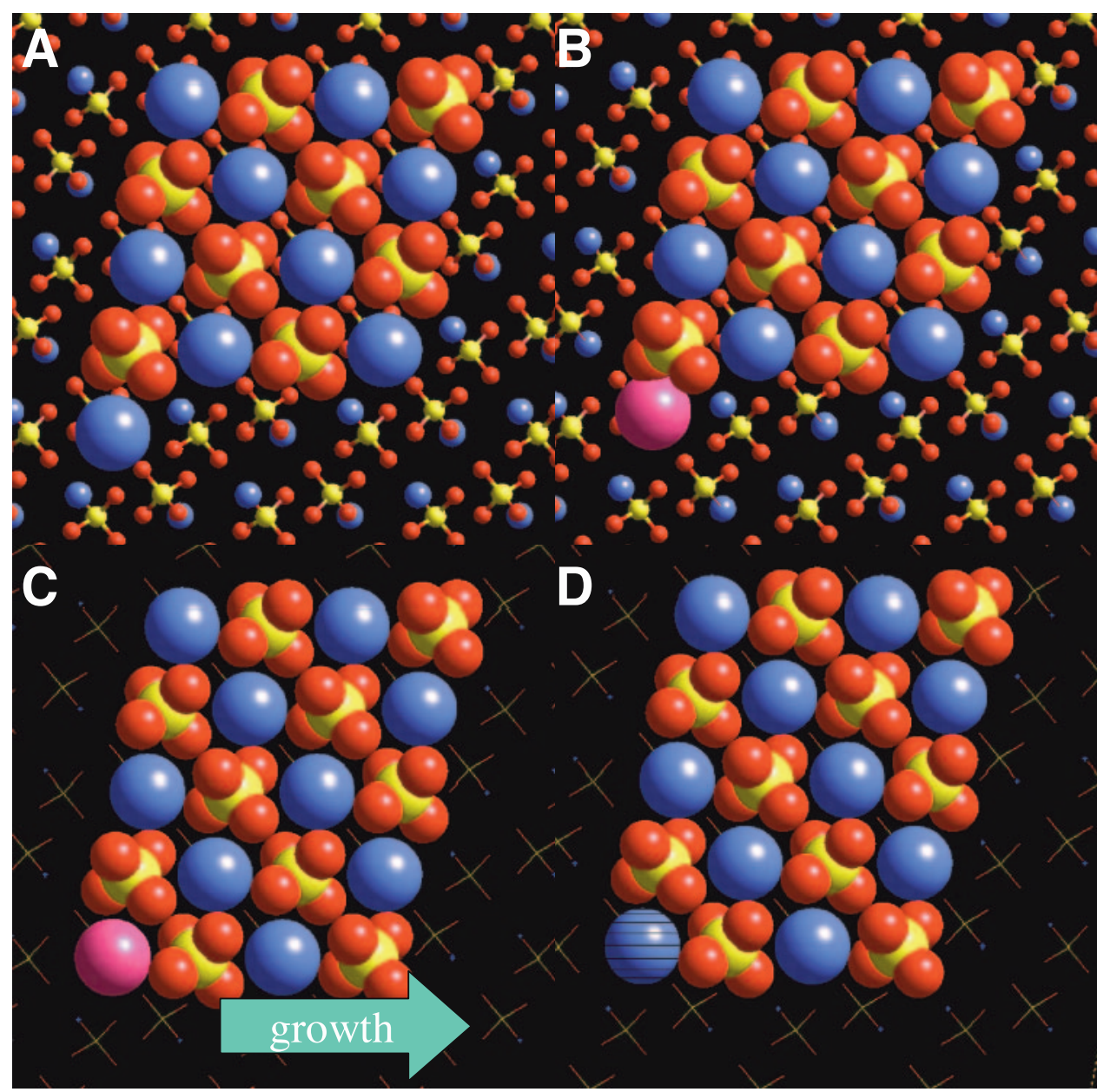

Fig. 8. (A) In pure $\mathrm{BaSO}_{4}$, the rate-limiting step is the initial formation of a new growth row because the attachment of $\mathrm{Ba}^{2+}$ is slightly endothermic (see text for calculation of attachment energy). (B) The formation of a temporary kink site by a $\mathrm{Na}^{+}$ion is energetically more favorable. After the continuous growth of $\mathrm{BaSO}_{4}$ row (C), energy can be gained by substituting the first $\mathrm{Na}^{+}$ion in the row by a $\mathrm{Ba}^{2+}$ ion (D) (modified from Becker and others, 2002).

THE INTERACTION OF ORGANIC GROWTH INHIBITORS WITH MINERAL SURFACES

For the interaction of organic molecules with sulfate surfaces, we can use a similar methodology as derived for the adsorption of monovalent inorganic ions. It is important to understand the influence of organic molecules on sulfate growth because certain organic molecules, such as phosphonic and carboxylic acids, have the ability to retard or totally inhibit crystal growth from solution. In order to understand, predict, and control crystal growth, knowledge of the molecular mechanisms that govern the inhibitor-crystal interaction is necessary. Considerable research has focused on designing additive molecules that modify crystal growth in a predictable way ( $\mathrm{Li}$ and Mann, 2000; Qi and others, 2000). It was found that at least two phosphonate groups are required to inhibit barite growth (with a three-atom chain between the phosphonate groups, Black and others, 1991). Different phosphonate inhibitors have been designed and shown to be effective (Davey and others, 1991; Rohl and others, 1996; Coveney 
<smiles>CC(O)(P(=O)(O)O)P(=O)(O)O</smiles><smiles>O=P(O)(O)C(P(=O)(O)O)P(=O)(O)O</smiles><smiles>NCP(=O)(O)O</smiles>

AMP<smiles>CN(C(N([PH3])P(=O)(O)O)P(=O)(O)O)P(=O)(O)O</smiles><smiles>O=C(O)CCC(CC(=O)O)(C(=O)O)P(=O)(O)O</smiles>

PBTC

Fig. 9. Schematic representation of the five phosphonates used in this work as inhibitors of the growth of the barite $\left(\begin{array}{lll}0 & 0 & 1\end{array}\right)$ face (modified from Pina and others, 2004).

and others, 1998, 2000; Jones and others, 2001, 2002). Jones and others (2001) substituted carboxylic groups for phosphonate groups in order to minimize structural changes in the molecules and compared inhibition efficiency with decreasing numbers of phosphonate groups. In addition to designing more effective inhibitor molecules for industrial applications, studying the effect of organic molecules on crystal growth is a first step toward understanding biomineralization.

Traditionally, the adsorption of molecules to mineral surfaces has been indirectly investigated from bulk experiments. Measurements of crystallization rates in the presence of inhibitors have been attributed to the adsorption of molecules to active growth sites on surfaces (Cabrera and Vermilyea, 1958; Sangwal, 1998). Thus, by experimental determination of adsorption isotherms, it is possible to interpret crystal growth behavior in the presence of a wide variety of inorganic and organic additives. The in situ observation of surfaces during growth using AFM in combination with molecular simulations helps us to understand the effect of inhibitors on the thermodynamics and kinetics of crystal growth at the molecular scale (Bosbach and others, 1996, 2002). Here, we describe the inhibiting effect of five polyphosphonic acids, hydroxyethylene diphosphonic acid (HEDP), nitro trimethyl phosphonic acid (NTMP), methylene diphosphonic acid (MDP), amino methylene phosphonic acid (AMP), and sodium phosphonobutane tricarboxylic acid (PBTC, fig. 9).

After the (i) qualitative description of the microtopography of growing surfaces in the presence of the inhibitors (changes in the shape of both growth steps and two-dimensional nuclei, nucleation density, et cetera); (ii) the dependence of growth rates of monomolecular steps on inhibitor concentration and adsorption isotherms was analyzed, which allows us to quantitatively compare the effectiveness of the inhibitors. Next, (iii) the molecular modeling and energy calculations of the interac- 


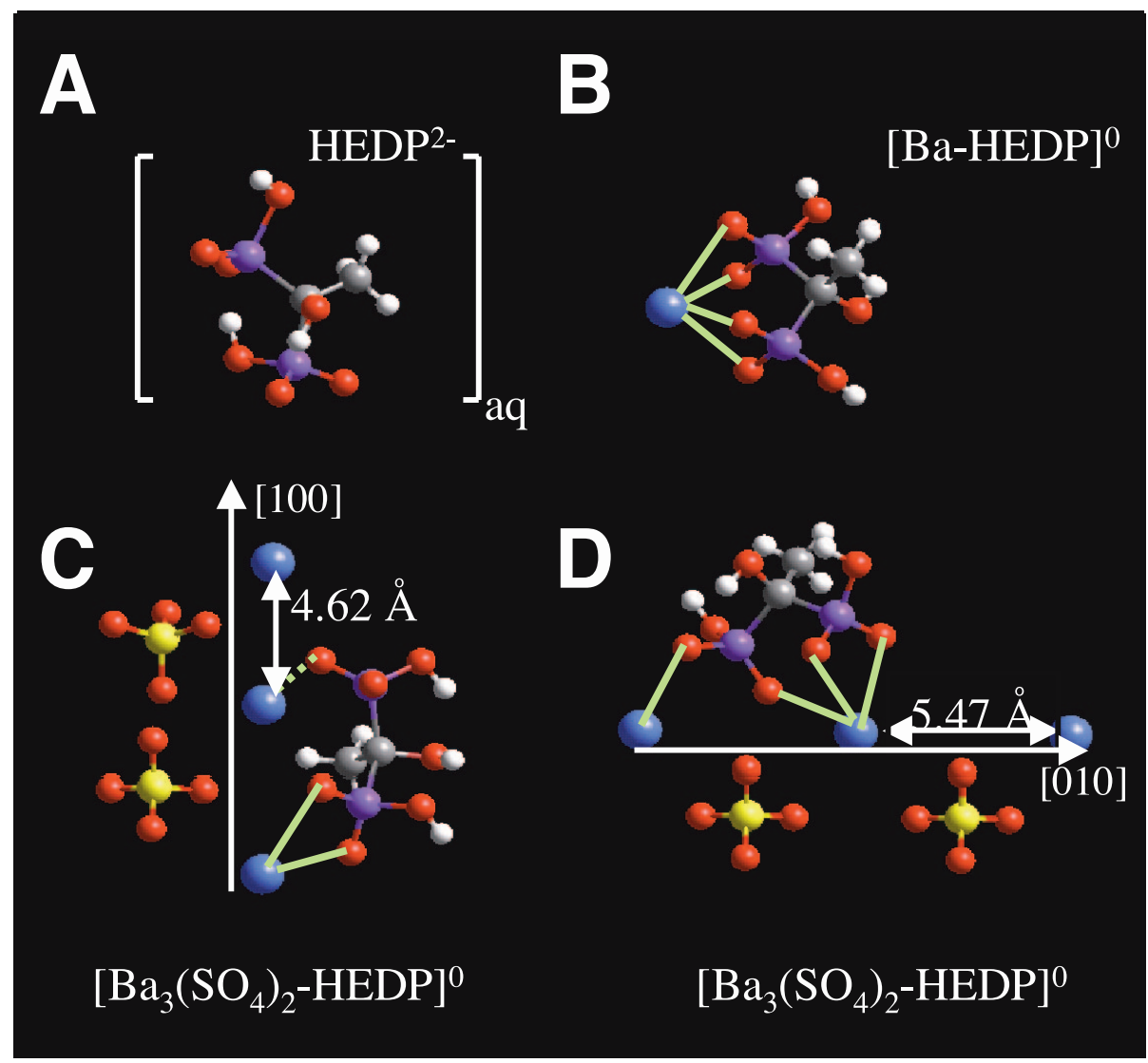

Fig. 10. $\mathrm{H}_{2}$-HEDP-fragments used in quantum mechanical calculations (GAUSSIAN98) to derive force field potentials (modified from Becker and others, 2002).

tion of the five phosphonic acids with the barite (001) face were used to study the role of different surface sites as potential adsorption sites.

Finally, in order to obtain a general view of the adsorption process and its inhibiting effectiveness, the microtopographic observations and the quantitative information provided by both adsorption isotherms and growth rates of monomolecular steps are discussed, together with molecular modeling of the inhibitor-crystal interface.

First we follow the same approach as described for the adsorption of monovalent ions to polar steps. For the interaction between HEDP and the barite surface, we derived empirical potentials from quantum mechanical calculations using molecular fragments (fig. 10) and the program Gaussian (Frisch and others, 1998) as described in Becker and others (2002). One can compare the adsorption of one $\mathrm{SO}_{4}{ }^{2-}$ or two $\mathrm{Cl}^{-}$ ions with the adsorption of $\mathrm{H}_{2}-\mathrm{HEDP}^{2-}$ to the same steps. A sulfate ion in the "jagged step" picture (analogous to fig. 4 but with sulfate bounding) can either be replaced by two chloride ions or one $\mathrm{H}_{2}-\mathrm{HEDP}^{2-}$ ion. Where substitution of $\mathrm{SO}_{4}{ }^{2-}$ is still a competitive process, the adsorption of $\mathrm{H}_{2}-\mathrm{HEDP}^{2-}$ to either [100] or [010] steps or the adsorption to kink sites on $\tau$ steps is much stronger and thus irreversible. This explains why sites in the experimental images with $\mathrm{H}_{2}-\mathrm{HEDP}^{2-}$ bonded to them are pinned during step advancement (Sangwal, 1998) and no dynamic exchange can take place 


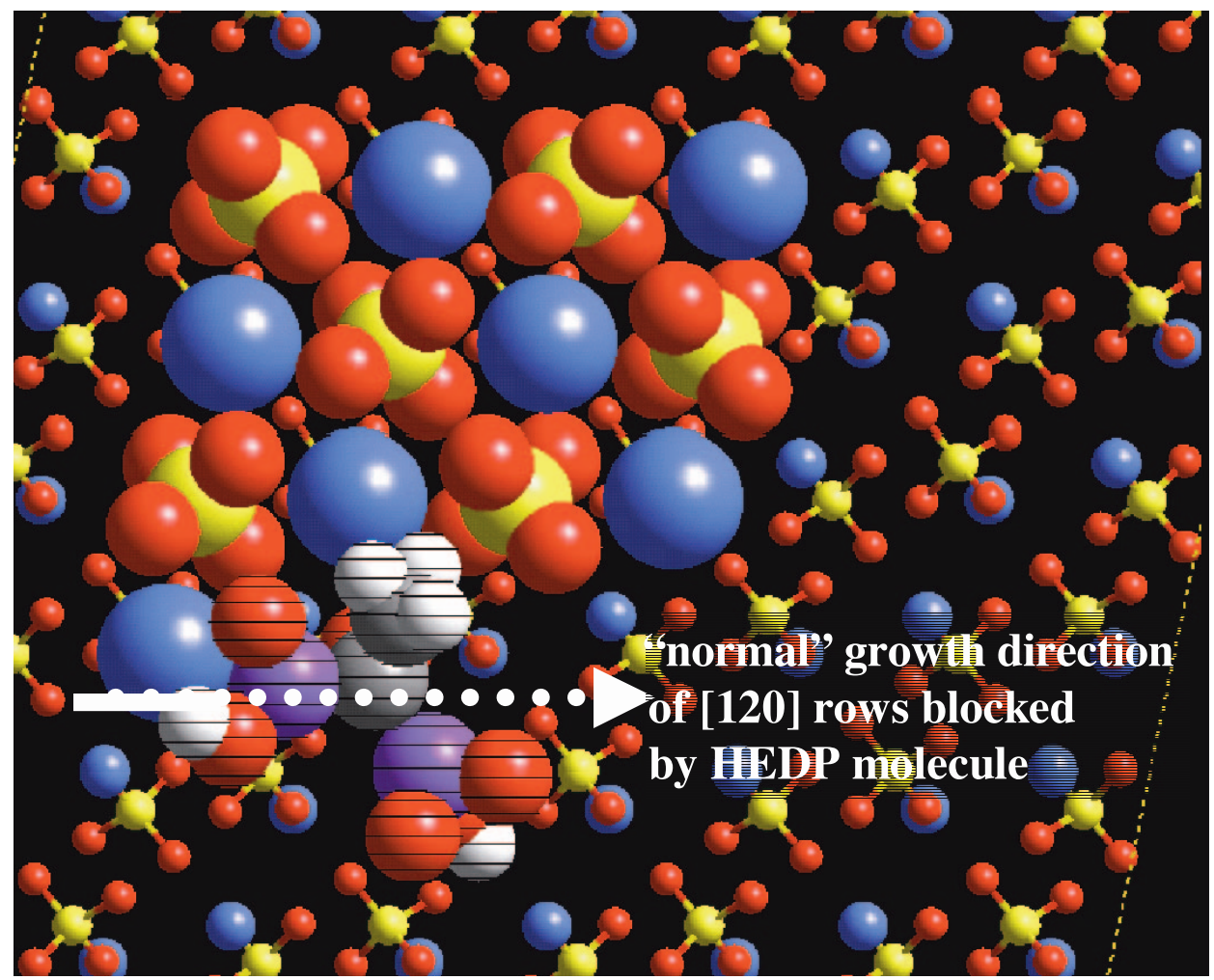

Fig. 11. Kink-blocking mechanism by $\mathrm{H}_{2}-\mathrm{HEDP}^{2-}$ (modified from Becker and others, 2002).

that leads to the formation of straight, crystallographically oriented steps. Even though concentrations that are typically used for growth inhibitors such as HEDP are in the $\mu \mathrm{mol}$ range and, thus, adsorption occurs in form of single diphosphonate ions adsorbed to steps, the co-adsorption of $\mathrm{H}_{2}-\mathrm{HEDP}^{2-}$ to neighboring sites stabilizes such an adsorption site even more due to the formation of hydrogen bonds between neighboring diphosphonate ions.

Figure 11 shows the most likely structure of HEDP adsorption. One of the phosphonate groups binds to the $\mathrm{Ba}^{2+}$ ions at a kink site and inhibits the continuous growth of that particular $\mathrm{BaSO}_{4}$ growth row. Since the binding energy of the $\mathrm{H}_{2-}$ $\mathrm{HEDP}^{2-}$ to this kink site is much stronger than the binding energy of a sulfate ion to this site, growth is permanently inhibited. The only possibility to continue growth would be that the $\mathrm{H}_{2}$-HEDP ${ }^{2-}$ gets overgrown.

Details on the experimental approach to derive adsorption isotherms from AFM experiments can be found in Pina and others (2004). In brief, barite (001) surfaces were exposed to aqueous solutions with a concentration of $40 \mu \mathrm{mol} / 1 \mathrm{BaSO}_{4}$, which were injected into the fluid cell. This concentration is high enough to promote moderate two-dimensional nucleation (Bosbach and others, 1998). Once the nuclei grew to $\sim 100 \mathrm{~nm}$ along the [100] direction, solutions with the same $\mathrm{BaSO}_{4}$ concentration but containing a range of concentrations $(0.5-60 \mu \mathrm{mol} / \mathrm{l})$ of HEDP, NTMP, MDP, AMP and PBTC were passed over the crystal surfaces and the growth rates of monomolecular steps on barite (001) faces in the presence of inhibitor were measured. 
Molecular simulations of in-vacuo adsorption energies were performed on a barite (001) cluster containing 2484 atoms, that is, $414 \mathrm{BaSO}_{4}$ formula units (details can also be found in Pina and others, 2004). The cluster was bounded by periodic bond chains $(\langle 120\rangle$ direction and its symmetry equivalents) such that there was no dipole moment perpendicular to the surface and none parallel to the edges of the cluster. This is important in order to avoid surface instabilities and to avoid long-range interactions between the cluster and the adsorbate that are caused by the cluster construction rather than the interaction of the growth inhibitor molecule with a specific surface site. For the calculation of in-vacuo adsorption energies, we used the species $\mathrm{AMP}^{-1}, \mathrm{AMP}^{2-}$, $\mathrm{MDP}^{2-}, \mathrm{HEDP}^{2-}$, NTMP ${ }^{2-}, \mathrm{NTMP}^{4-}, \mathrm{PBTC}^{2-}$, and $\mathrm{PBTC}^{4-}$; the change in hydration energies from the dissolved state to the adsorbed one was calculated subsequently. Molecular mechanics and molecular dynamics calculations with subsequent energy optimizations were used to find absolute absorption minima for each surface site. All calculations were performed using empirical force fields, derived by Allan and others (1993) for interactions within the barite crystal, so-called Universal Force Fields by Rappe and others (1992) for interactions within the inhibitor molecules, and by Becker and others (2002) for interactions between the phosphonates and the crystal surface.

The presence of inhibitor in solution reduces the growth rates and, especially in the case of HEDP and AMP, changes the morphology of the islands. In order to quantify the inhibiting effect of the HEDP, NTMP, MDP, AMP and PBTC molecules, we have measured growth rates along the [100] directions of two-dimensional island growth on the barite (001) face for each inhibitor and for different concentrations. We derived the normalized $v_{i} / v_{0}$ step velocities (where $v_{i}$ and $v_{0}$ are the growth rates along [100] with and without inhibitor, respectively) as a function of inhibitor concentration. A rapid decrease in step advancement rates can be found for inhibitor concentrations lower than $10 \mu \mathrm{mol} / \mathrm{l}$ (Pina and others, 2004). After this initial decrease, the inhibiting effect of the phosphonic acids becomes weaker and for further increase in inhibitor concentration, the retardation of the step advancement reaches a plateau with little dependence between growth rate and inhibitor concentration. The extension and slope of the plateaus are different for each phosphonic acid. Only for PBTC, complete inhibition for molecule concentrations higher than $10 \mu \mathrm{mol} / 1$ is observed.

\section{Derivation of Adsorption Isotherms from AFM Growth Experiments}

In order to compare the effectiveness of the organic molecules, HEDP, NTMP, MDP, AMP and PBTC, we have represented the step rates and inhibitor concentrations using Langmuir diagrams. In such diagrams, the $v_{0} /\left(v_{0}-v_{i}\right)$ parameter, calculated from growth rates of individual monomolecular steps, is plotted against the inverse of the inhibitor concentration, $[\operatorname{Inh}]^{-1}$. Table 1 shows the approximately linear relationship of $v_{0} /\left(v_{0}-v_{i}\right)$ as a function of $[\operatorname{Inh}]^{-1}$ for the five inhibitors studied (linearity expressed by the respective correlation coefficients). This means that the mechanisms of inhibition within the error of experiment can be satisfactorily described by Langmuir adsorption isotherms:

$$
v_{0} /\left(v_{0}-v_{i}\right)=k_{0}+k_{1}[\operatorname{Inh}]^{-1}
$$

where $k_{0}$ is 1 for complete inhibition; $k_{1}$ is the so-called "affinity constant", indicative of the effectiveness of the inhibitor, that is, its ability to retard the step advancement (Amjad, 1995). Therefore, the lower the $k_{1}$ value, the more effective the inhibitor. Table 1 shows the affinity constants for HEDP, NTMP, MDP, and PBTC inhibitors (column 3) obtained from our AFM experiments.

In order to compare the thermodynamics of adsorption from the experimental results with molecular simulations, we calculated adsorption energies of inhibitor 
TABLE 1

Adsorption parameters for HEDP, NTMP, MDP, AMP and PBTC on barite (001) face at room temperature (see equation 1) and AFM observations of the effect of the inhibitor on the barite (001) surface. $k_{0}$ and $k_{1}$ are derived from the growth velocities $v_{0}$ (growth velocity without inhibitor) and $v_{i}$ (velocity with inhibitor) as a function of the inverse of the inhibitor concentration [Inh $]^{-1}$ using $v_{O} /\left(v_{O}-v_{i}\right)=k_{O}+k_{1}[\operatorname{Inh}]^{-1}$.

\begin{tabular}{ccccc}
\hline Inhibitor & $k_{0}$ & $k_{l}$ & $\begin{array}{c}\text { Correlation } \\
\text { coefficient }\end{array}$ & AFM observations \\
\hline HEDP & 0.927 & $4.252 \times 10^{-6}$ & 0.95 & irregular islands \\
NTMP & 1.684 & $1.300 \times 10^{-6}$ & 0.59 & circular sector islands \\
MDP & 1.261 & $3.030 \times 10^{-6}$ & 0.92 & circular sector islands \\
AMP & 3.514 & $36.79 \times 10^{-6}$ & 0.63 & irregular islands \\
PBTC & 0.898 & $1.848 \times 10^{-6}$ & 0.92 & circular sector islands \\
\hline
\end{tabular}

molecules to flat terraces, straight edges, outer and inner corners of islands, and to kink sites of growth islands. We found that when hydration energies are taken into account, inhibitor adsorption to flat terraces is energetically uphill. For straight steps, only for NTMP ${ }^{2-}$, adsorption to the side of unperturbed steps seems to be likely within the error of calculation.

All inhibitor molecules gain energy by adsorbing to corner sites in a hydrated environment. It is interesting to note that the phosphonates (AMP, MDP, HEDP, and NTMP) prefer the configuration where $\mathrm{Ba}^{2+}$ is located at the obtuse corner whereas PBTC prefers to adsorb to $\mathrm{Ba}^{2+}$ at an acute corner.

For each molecule, there is also a kink site configuration for which adsorption is energetically downhill. Kink sites are likely the most important sites for crystal growth blocking. We found the most energetically favorable kink site/phosphonate bond for NTMP $^{4}$. However, it may be more valid to consider all 22 kink-site configurations that we evaluated. For PBTC ${ }^{4}$, all adsorption energies in a hydrated environment for binding to any of the kink sites are negative (average is $-1.36 \mathrm{eV}$ ) whereas this is only the case for about half (12 out of 22) of the adsorption events for $\mathrm{NTMP}^{4-}$ (with an average of $-0.86 \mathrm{eV}$ ). This ratio may even become worse if we consider that kink sites lose most of the hydration energy during adsorption at the site types that we consider. This indicates that whatever the type of kink site, it can be blocked by PBTC $^{4-}$, but about half the kink sites can continue growing if $\mathrm{NTMP}^{4-}$ is the chosen inhibitor.

The fact that the initial adsorption follows the behavior predicted by Langmuir's model implies that the inhibiting effect of the organic molecules studied in this work on barite is due to the attachment of molecules on active growth sites. Our calculations indicate that these active sites are kink sites located along steps. Adsorption to corners is also exothermic, but on most growth islands, there are many more kink than corner sites. In all cases of kink site adsorption, the adsorption energies are higher than $0.4 \mathrm{eV}$ $(\approx 40 \mathrm{~kJ} / \mathrm{mol})$. Such high adsorption energies mean that the adsorption has a chemical character, that is, the inhibitor-active site bonds are quite strong (typical energies for physical adsorption are lower than $40 \mathrm{~kJ} / \mathrm{mol}$ while for a chemical adsorption values up to and even over a hundred $\mathrm{kJ} / \mathrm{mol}-0.4$ to $<1 \mathrm{eV} /$ adsorbed inhibitor molecule - are expected; Brixner, 1967).

Other possible positions for adsorption, such as flat terraces or steps without kinks or defects provided positive adsorption energies, indicating that they are negligible as positions for crystal growth blocking. This is in agreement with the observed growth rate-inhibitor concentration plateaus for high concentration of inhibitor. Thus, once all kink sites along the steps on the barite (001) surface are occupied with inhibitor 
molecules, the effectiveness of the inhibitor reaches a maximum and a further increase in the inhibitor concentration does not lead to a significant decrease in growth rates because no more adsorption positions are available on the crystal surface. Only when the concentration of inhibitor in the solution is very high (above $10 \mu \mathrm{mol} / \mathrm{l}$ or 20 $\mu \mathrm{mol} / \mathrm{l})$, a layer of inhibitor molecules can be formed on the barite surface. However, since the adsorption energies of the inhibitor on terraces are positive, no adsorption can be expected. The observed covering must be, therefore, interpreted as a flocculation of inhibitor molecules on the barite (001) surfaces. Nevertheless, such a layer can prevent the barite growth units reaching the surfaces acting as "physical barrier" for the growth process and completely stop growth.

The strength of the adsorption of inhibitor molecules on kink sites can also be quantified through the affinity constants, $k_{1}$, in equation (2) (see table 1). These constants are in the same range as those obtained by Amjad (1995) for the adsorption of phosphonates on calcium phosphate from bulk experiments (Amjad, 1995, reported $k_{1}$ values of $8 \cdot 10^{-6}, 17 \cdot 10^{-6}$ and $31.2 \cdot 10^{-6}$ for PBTC, HEDP, and AMP, respectively). By considering both the ranking of our measured constants and the behavior of the inhibitors for high concentrations, our data suggest the following order of inhibiting effectiveness for the phosphonates: PBTC $>$ NTMP $>$ MDP $>$ HEDP $>>$ AMP. This ranking is consistent with the ranking obtained by Amjad (1995): PBTC $>$ HEDP $>$ AMP (Amjad, 1995, did not study the behavior of MDP and NTMP).

Another interesting aspect of the inhibiting phenomenon is the change in the shape of the islands (see last column in table 1). Our AFM observations indicate that, while in the presence of HEDP and AMP, barite islands become irregular after a short time, the other inhibitors tested do not promote such pronounced changes in island shape, which essentially remain with their typical circular sector shape. Since HEDP and AMP are less effective inhibitors, the change in island shape can be attributed to a weaker attachment of these molecules to the active site along steps that can result in a continuous adsorption and desorption of inhibitors on those positions. This would imply that growth positions would be no longer blocked, resulting in an isotropic irregular shape with time. In contrast, PBTC, NTMP and MDP are able to block kink sites along monomolecular steps in a more efficient (and permanent) way. As a consequence, growth is more strongly inhibited but the shape of the islands is preserved.

\section{AZOTOBACTIN-GOETHITE/DIASPORE INTERACTIONS}

As a next step to increase the complexity in the interaction between organic molecules and minerals, we chose siderophore-mineral interactions. Siderophores, organic ligands commonly produced by soil bacteria and fungi, are known to dissolve iron-containing minerals (Hersman and others, 1995) in a process that is independent of the presence of the microorganisms that produced them (Hersman and others, 1996). The associated influence that siderophores have on iron cycling makes them a potentially significant geochemical force and an important factor in microbial ecology. Computational work on siderophores has focused on the stable aqueous complex these ligands form with Fe(III) (Hay and Rustad, 1994; Hay and others, 1996, 2001; Lumetta and others, 2002), but only a limited amount of mechanistic information on their interaction with mineral surfaces exists. Adsorption, kinetic, and spectroscopic studies of hydroxamate and catecholate siderophores (Hansen and others, 1995; Holmen and Casey, 1996; Kraemer and others, 1999; Kalinowski and others, 2000; Liermann and others, 2000; McWhirter and others, 2003) suggest the formation of a surface complex between siderophore oxygens and metals on the iron oxide surface, a process that Holmen and Casey (1996) speculate to proceed via ligand exchange, at least for hydroxamate siderophores. A recent bulk solution study suggests goethite dissolution may proceed via a two-ligand, synergistic interplay between the sid- 
erophore desferrioxamine (DFO) and smaller chelators such as oxalate (Cheah and others, 2003). DFO adsorption to the surface is predicted to be less important; instead, the siderophore chelates iron from oxalate in solution, renewing the smaller ligand's ability to dissolve more iron from the mineral (Cheah and others, 2003). We believe this to be a likely scenario, however, using azotobactin as a model siderophore, our calculations provide additional evidence of strong siderophore-mineral surface affinity and reactivity.

In our previous work, we demonstrated that force measurements made using an Atomic Force Microscope (AFM) were useful in examining the siderophore-mineral interactions by providing direct molecular-level quantitative force data (Kendall and Hochella, 2003). Specifically, these data showed that the siderophore azotobactin exhibits a degree of mineral specificity that favors iron over aluminum oxides. Our molecular simulations of azotobactin-diaspore $(\alpha-\mathrm{AlOOH})$ and azotobactin-goethite $(\alpha-\mathrm{FeOOH})$ interactions are designed to complement and more fully understand, at least in a qualitative framework, these experimental force measurements, while further evaluating the notion of surface reactivity as a component in siderophore-mediated mineral dissolution. Specific aims include determining which siderophore functional groups attach to the surface and characterizing the nature and geometry of these coordinations. This includes evaluating the question if there are any steric hindrances in forming a multi-bonded complex between the surface metal atom and the siderophore while the latter is adsorbed to the surface. In addition, these calculations were used to discriminate between relatively weak and strong linkages using energydistance profiles and derived forces. Using these simulated forces, we make a qualitative comparison with experimental forces to see if the same distinction in goethite and diaspore force signatures observed using the AFM can be predicted by the model. Additional separate quantum mechanical calculations on azotobactin fragments bonded to a single $\mathrm{Fe}$ or $\mathrm{Al}$ atom were also completed to assess the source of specificity (for example, electron affinity) between chelating $\mathrm{O}$ atoms and $\mathrm{Fe}$, and to complement the empirical force-field calculations on the whole system by deriving $\mathrm{Fe}_{\text {mineral }} / \mathrm{Al}_{\text {mineral }}$ siderophore specific potentials. The effect of the interaction on the metal in the mineral structure was also examined with a specific question in mind: Is "dissolution" observed under any of the simulated, albeit simplified, conditions? For example, does azotobactin, in contact with the mineral surface in vacuum, or under hydrated conditions simulated with a constant dielectric field or with added water clusters, completely extract a cation from the oxide surface?

\section{Molecular Mechanics Methodology of Siderophore-Oxide Interactions}

Simulations were carried out using the Cerius ${ }^{2}$ computational package (Accelrys, Inc.). In order to develop a set of empirical potentials (for example, Buckingham potentials, Gale, 1998) that mimic the physico-chemical properties of goethite and its isostructural Al-equivalent diaspore, we used the program package GULP (Gale, 1998). The interactions within the siderophore molecule are simulated by using the Universal Force Field (UFF) (Rappe and others, 1992) in combination with Coulomb potentials derived by using the Qeq charge equilibration scheme (Rappe and others, 1992). We derived potentials for the interactions between the chelating functional groups of the siderophore and the metal ions on the surface ( $\mathrm{Fe}, \mathrm{Al})$ using a quantum mechanical approach. Details on the computational methods can be found in Kendall and others (2005).

Hydrated environments of siderophore-metal fragments were modeled as a continuum of uniform dielectric constant using Tomasi's Polarized Continuum Model (PCM) (Miertus and Tomasi, 1982) on quantum mechanically optimized vacuum structures. It should be noted that the PCM of solvation is somewhat inaccurate, especially for small ions. However, use of the model on larger organic fragments results 


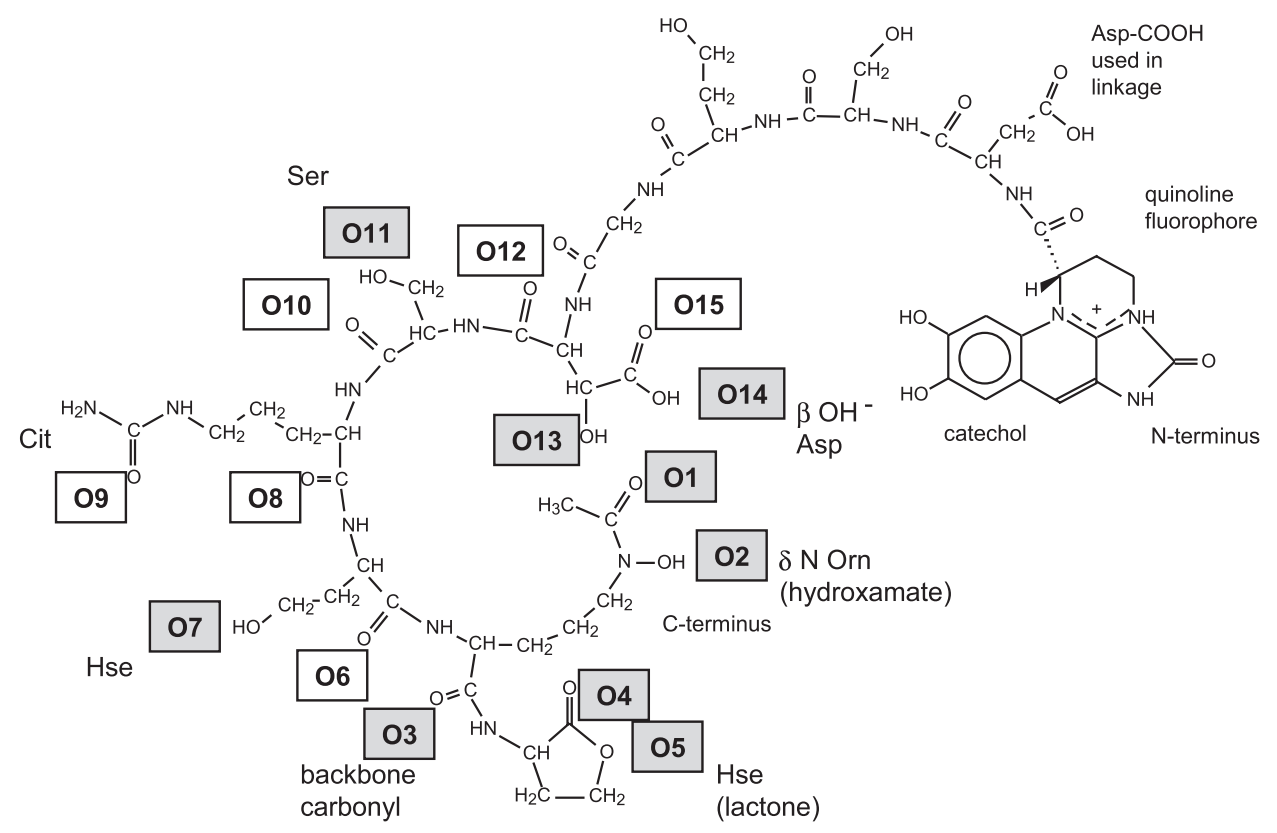

Fig. 12. Annotated azotobactin structure (Palanche and others, 1999) with oxygens numbered in series; those with shaded boxes coordinated with metals on the mineral surface during the simulation. Ser $=$ serine; Asp = aspartic acid; Orn = ornithine; Hse = homoserine. The hydroxycarboxylic acid $(\beta \mathrm{OH}-\mathrm{Asp})$, the hydroxamate ( $\delta \mathrm{N}$ Orn) and catechol moieties are known to chelate aqueous metals including $\mathrm{Fe}^{3+}(\mathrm{aq})$ (modified from Kendall and others, 2005. Reprinted from Chemical Geology, Modeling of azotobactingoethite/diaspore interactions: Applications to molecular force measurements and siderophore-mineral reactivity, p. 17-35, with permission from Elsevier.).

in comparatively lower errors and, thus, provides a sufficient approximation. In addition, fragments of the siderophore with two functional groups and their $\mathrm{Fe} / \mathrm{Al}$ chelates were calculated as a hydrated complex using a quantum mechanical approach (B3LYP, HF/DFT hybrid, Becke-3-parameter-Lee-Yang-Parr, Lee and others, 1988; Becke, 1993) with a 6-31g Pople-type basis set, by completing the hydration environment of the metal cation with four water molecules.

\section{Methodology of Azotobactin and Azotobactin-Mineral Molecular Mechanics Simulations}

Most of the molecular mechanics simulations were performed using vacuum conditions (dielectric constant $\epsilon=1$ ) to reduce computation time; however, solvated conditions in selected runs were simulated by increasing the dielectric constant $(\epsilon=$ 80 ) or adding clusters of individual water molecules to the system. The azotobactin molecule was constructed based on the structure provided by Palanche and others (1999) (fig. 12). To facilitate discussion of the siderophore structure, each $\mathrm{O}$ atom has been numbered according to figure 12. This numbering system is referred to when describing the $\mathrm{O}$ atoms that coordinate and release from each surface or the free $\mathrm{Fe}^{3+}$ ion. Coordination or bonding to the surface was defined as when the Fe/Al-O (siderophore oxygen) distance is less than $2.2 \AA$. For larger distances, the combination of Lennard-Jones and Coulomb potentials, as implemented by the Universal Force Field is in good agreement with our quantum mechanical results.

Similar to the AFM experimental conditions (Kendall and Hochella, 2003), a hydrazide $\left(-\mathrm{NH}_{2}\right)$ terminated 11 carbon linker molecule was attached to the azotobactin via a peptide bond to the Asp carboxyl group (fig. 13). A gold atom was added to the 


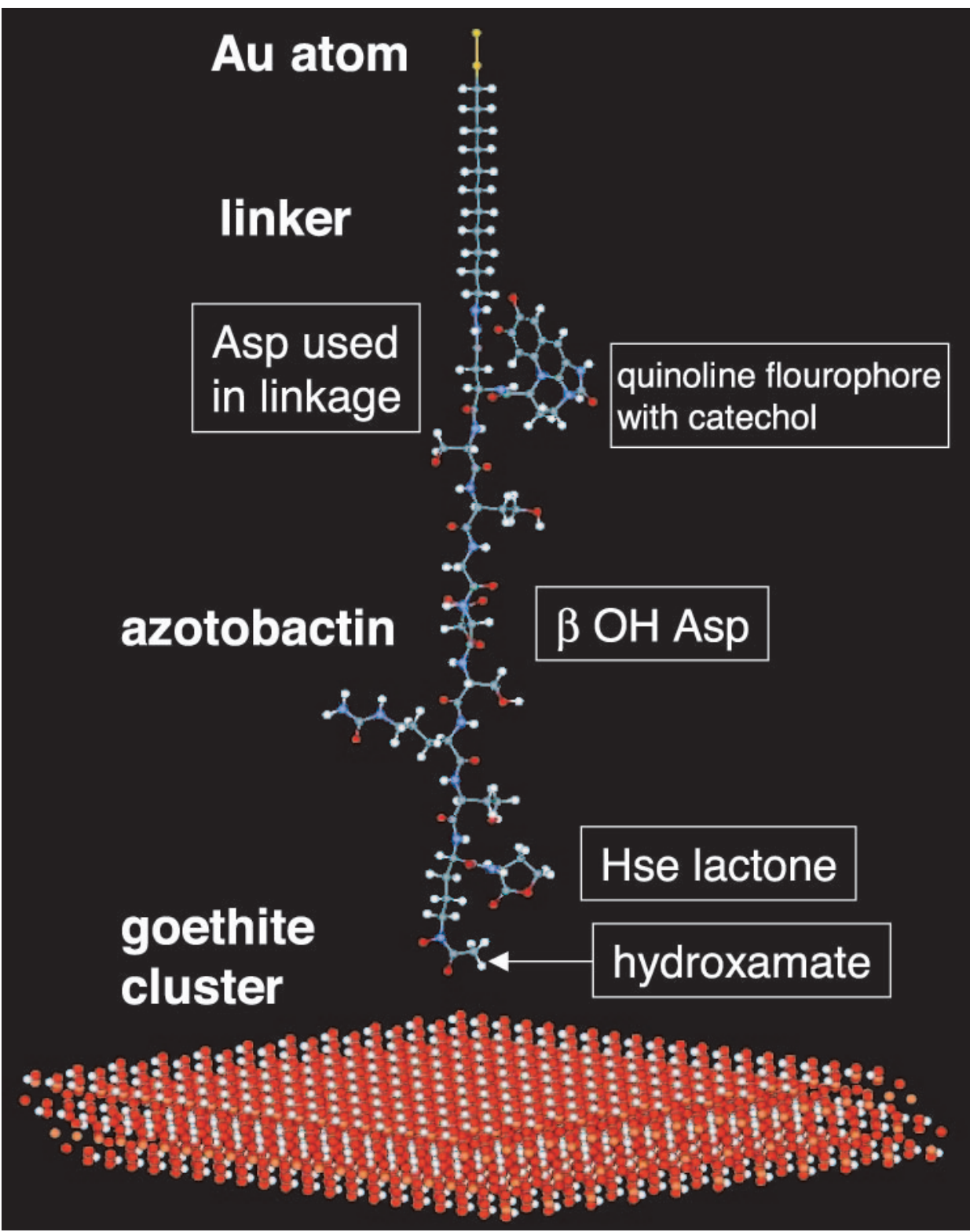

Fig. 13. Starting point of extension simulation with linearized azotobactin molecule approaching the goethite cluster. Note that chelating oxygens associated with the hydroxycarboxylic acid, hydroxamate and catechol groups are modeled in a deprotonated state (modified from Kendall and others, 2005. Reprinted from Chemical Geology, Modeling of azotobactin-goethite/diaspore interactions: Applications to molecular force measurements and siderophore-mineral reactivity, p. 17-35, with permission from Elsevier.).

end of the linker molecule to represent the gold coating on the AFM tip. The Au atom position was fixed and thus, the manual modification of the distance between the $\mathrm{Au}$ atom and the mineral cluster by small increments was used to simulate the approach and the retraction of the tip. For each calculation for a given Au (tip)- mineral separation, all atoms in the azotobactin and linker molecule were allowed to relax to 
energy-optimized positions or allowed to move in molecular dynamics simulations. While molecular mechanics energy-optimizes a structure (in this case an organic molecule plus mineral cluster) at $0 \mathrm{~K}$, several cycles of molecular dynamics (MD) with subsequent energy optimizations ensure that the system does not get trapped in local energy minima that do not represent the fully optimized structure.

The azotobactin molecule was brought into contact with both a single $\mathrm{Fe}^{3+}$ atom and the (010) face of goethite and its isostructural Al-equivalent diaspore. Each simulated mineral surface consisted of a stoichiometric $20 \times 11 \times 4$ unit cell cluster that was charge-neutral. The cluster was terminated in such a way that there was no dipole moment perpendicular to the surface. However, under aqueous conditions at circumneutral $\mathrm{pH}$, the surface of goethite is positively charged (Cornell and Schwertmann, 1996) and azotobactin is negatively charged (Telford and Raymond, 1996). Our simulation using a neutral surface, therefore, does not include this possible long-range electrostatic interaction. Structural information for each mineral including cell parameters and fractional coordinates were obtained from the literature (Busing and Levy, 1958; Gualtieri and Venturelli, 1999). In order to separate the influence of compression/stretching force within the azotobactin from azotobactin-mineral surface interactions (included) and surface relaxation and bond formation/breaking in the surface (not included), the positions of atoms in the mineral cluster were fixed during the initial extension of the molecule towards the surface. Prior to the interaction, the siderophore-linker construct was fully extended by fixing the gold atom at the beginning of the linker and advancing the methyl carbon associated with the hydroxamate group towards the C-terminal end of the molecule in $0.5 \AA$ steps and minimizing the structure after each step. The result was a linearized conformation of the molecule (but not necessarily a global minimum energy state, fig. 13). This was completed to provide consistency and reproducibility in the interaction simulation, to insure functional groups were not hindered or prevented from interacting with the surface and to provide a starting condition that facilitates comparison between the two mineral systems.

After the stretching of the molecule, and prior to simulating the movement of the molecule toward the mineral surface, the hydroxamate methyl carbon was released, and allowed to move freely during minimizations. The Au atom remained fixed and AFM extension (approach) or retraction motion was modeled by decreasing or increasing, respectively, the distance between the gold atom and the mineral surface. The molecule was advanced in 0.3 to $1.5 \AA$ steps during extension and 0.5 to $1.5 \AA$ steps upon retraction. Note the vertical spatial resolution of the piezoelectric stage used in the AFM force measurements (Kendall and Hochella, 2003) is $\sim 1 \AA$. An optimization was completed after each step and the overall energy of the system plus interatomic distances between siderophore $\mathrm{O}$ atoms and surface bound metals were recorded. In addition, molecular dynamics (MD) calculations were performed, where the system was ramped to a temperature of $300 \mathrm{~K}$ followed by anneal dynamics (annealing cycles between $100 \mathrm{~K}$ and $300 \mathrm{~K}$ ) and a subsequent energy minimization.

\section{Results from the Simulation of Siderophore-Oxide Interactions}

Under the modeling conditions, the simulated force/energy distance curves can be separated into a number of events during approach/retraction:

- Successive formation/breaking of bonds between the azotobactin molecule and the surface (specifically Fe or Al on the surface),

- contraction, twisting and stretching of the azotobactin molecule into various conformations,

- displacement of an $\mathrm{Fe}$ or $\mathrm{Al}$ atom from its equilibrium position in the lattice,

- release of an $\mathrm{Fe}$ or $\mathrm{Al}$ atom from the surface, and 
- additional chelation of extracted metal atoms once other azotobactin groups are released from or desorbed from the surface.

\section{Simulated Approach Force Trace - Azotobactin and Goethite/Diaspore}

Upon approach of the azotobactin molecule to both the goethite and diaspore from a Au-surface separation of $63 \AA$ to $\sim 10 \AA$, the siderophore $\mathrm{O}$ atoms coordinate with metals on the surface in a sequence that is consistent with their relative position on the peptide backbone: the C-terminal groups (for example, the homoserine (Hse) lactone and hydroxamate moieties) coordinate first followed by groups closer to the ring structure at the N-terminus. This is expected because each amino acid was aligned in order upon stretching the molecule to a maximum contour length prior to the surface approach. Although it was not fixed and atomic motion was permitted, the linker molecule remained extended and rigid throughout the simulation. This is due to the fairly rigid bond and dihedral angles within the aliphatic linker molecules. As a result, the linker angles away from the axis of the extension and retraction, serving as a guide to lay the azotobactin molecule along its length onto the surface. The extension trace for each mineral is similar, with the diaspore curve essentially shifted down in relative energy scale due to the lowered lattice energy associated with diaspore and differences in the definition of the metal-oxygen interaction potentials associated with each mineral (fig. 14). All $\mathrm{O}$ atoms in both the peptide backbone and amino acid side chains had the potential to coordinate with metals in the surface. However, steric constraints imposed by the siderophore structure dictated which ones came close enough to ultimately interact. These included (in order of coordination to the surface): O1/O2 (hydroxamate), O4/O5 (Hse lactone), O3/O7 (backbone carbonyl $\mathrm{O}$ atom and Hse), O11 (Ser hydroxyl), O13/O14 ( $\beta$-hydroxyacid) (see also fig. 15). The slashes ("/") in the previous sentence indicate attachment of the two $\mathrm{O}$ atoms in the chelating group was approximately simultaneous.

It is interesting to note that the spacing of siderophore chelating pairs (for example, $\mathrm{O} 1 / \mathrm{O} 2, \mathrm{O} 4 / \mathrm{O} 5, \mathrm{O} 13 / \mathrm{O} 14$, and $\mathrm{O} 3 / \mathrm{O} 7$ ), allows roughly equidistant coordination to neighboring Fe atoms in the lattice (see fig. 14 as one example). In contrast, siderophore-sorption models based on bulk solution experiments on goethite speculate an oxygen pair coordinating with a single Fe (Holmen and Casey, 1996; Holmen and others, 1997) and not with neighboring Fe atoms. Also, two of three groups known to participate in the stable chelation of $\mathrm{Fe}(\mathrm{III})(\mathrm{aq})(\mathrm{O} 1 / \mathrm{O} 2$ hydroxamate and $\mathrm{O} 13 /$ O14 hydroxyacid) were sterically allowed to interact with the surface; however, $\mathrm{O}$ atoms associated with other groups such as Hse are important to the surface interaction as well. Other functional groups higher up the backbone (for example past O13/O14 $\beta$ hydroxyacid and closer to the quinoline group), including the catechol group that participates in chelation of the free aqueous iron, do not coordinate with the surface. This could be due to the steric restrictions imposed by their proximity to the linker molecule, or, in the case of catechol, a result of modeling the moiety in a deprotonated state. Snapshots of the extension simulation confirm this, where at $\approx 35$ $\AA$ Au-surface separation, the linker folds the azotobactin molecule back upon itself with the $\beta$ hydroxyacid (O13/O14) serving as a hinge point. While this behavior may be unique to the presence of the linker, and not necessarily reflective of a surface conformation typical in nature, it is interesting to note that a similar hydroxyacid hinge point position is observed in the proposed azotobactin-Fe(III) aqueous complex structure (see fig. 13). A second extension simulation was completed with a lateral component added to the downward motion. This was done to avoid generation of the hinge point and to stretch and lay the upper part of the molecule onto the mineral, thereby giving groups that are above the $\beta$ hydroxyacid an opportunity to interact with the surface. Additional coordination of groups closer to the Au atom (where the tip is) was, however, not observed. 

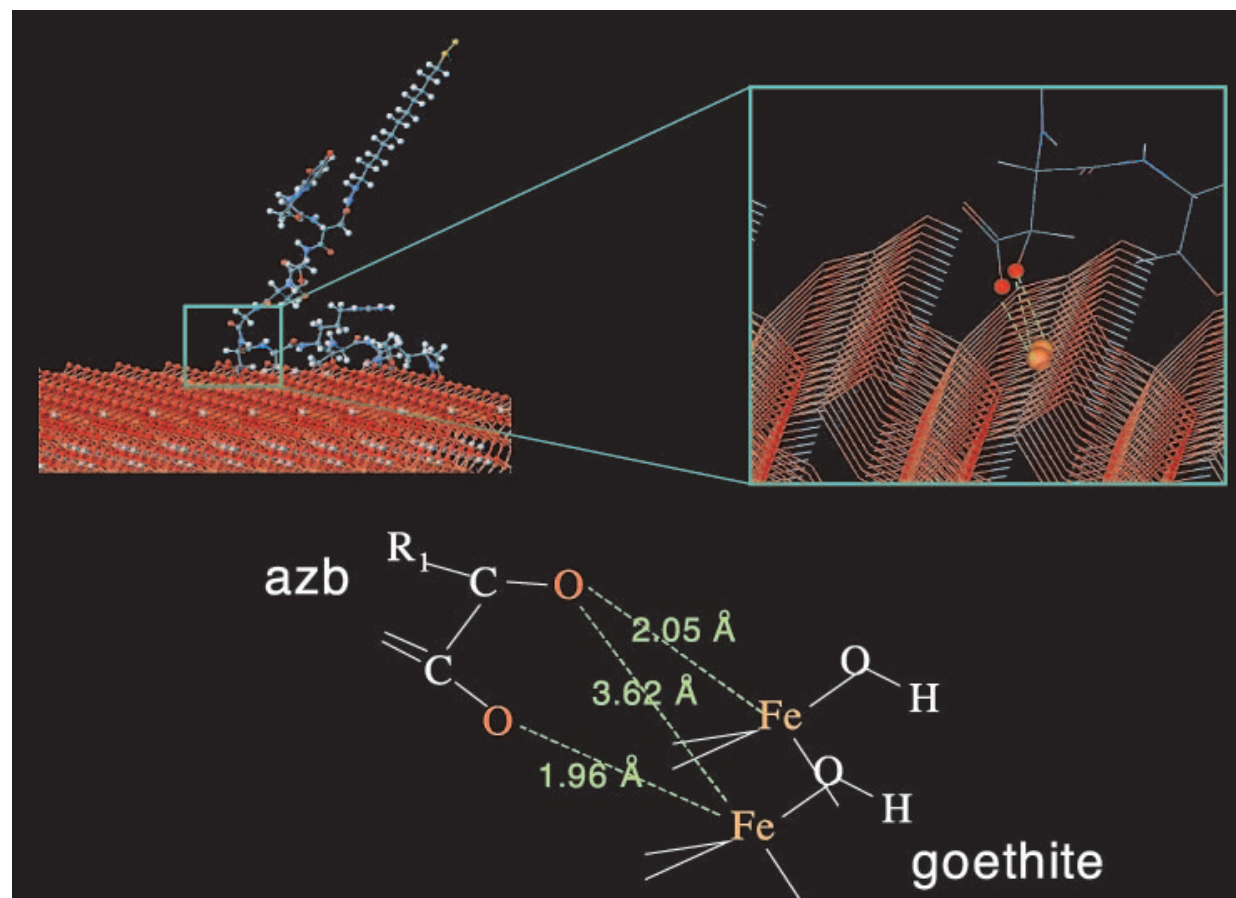

Fig. 14. Molecular models of azotobactin interacting with a goethite surface. From top to bottom, each image progressively 'zooms' in to the area of interest on the same model. Arrows point to hydroxamate group terminal oxygens coordinating with irons in the lattice in a binuclear fashion. Note the spacing of the siderophore oxygens allow for "bonds" (that is, $\mathrm{Fe}-\mathrm{O}$ (siderophore) distances $\sim 2 \AA$ ) with neighboring irons. With this coordination, the distance between a siderophore oxygen and an iron diagonally across is greater than $3 \AA$ (modified from Kendall and others, 2005. Reprinted from Chemical Geology, Modeling of azotobactin-goethite/diaspore interactions: Applications to molecular force measurements and siderophoremineral reactivity, p. 17-35, with permission from Elsevier.).

Aside from the unique structural constraints imposed for the purposes of simulating the AFM conditions, it is not surprising that some of the possible charge transfer groups, including the oxygens that participate in aqueous chelation of iron (that is, catechol), do not interact with the surface. A similar observation has been made when the siderophore desferrioxamine (DFO) interacts with goethite at circumneutral $\mathrm{pH}$ and ionic strengths similar to our experimental AFM conditions (Kraemer and others, 1999; Cocozza and others, 2002). DFO is a smaller ligand relative to azotobactin, and employs three hydroxamate groups linked by a methyl backbone to form a hexadentate aqueous complex with iron. However, when releasing iron from a solid form, multiple kinetic and adsorption experiments show that DFO has a pseudo-first order rate coefficient and an enthalpy/entropy relationship comparable to the singlehydroxamate ligand acetohydroxamic acid (aHA) $\left(\mathrm{C}_{2} \mathrm{H}_{5} \mathrm{NO}_{2}\right)$ (Holmen and Casey, 1996; Kraemer and others, 1999; Cocozza and others, 2002). This suggests a similar goethite dissolution mechanism for DFO and aHA, and, thus implies only one or two of the three DFO hydroxamate groups interact with the surface (Cocozza and others, 2002). Holmen and Casey (1996) postulate a reduction in the ligand's conformational freedom when proximal to the surface, the hydrophobicity of the DFO backbone, and the goethite structure all play a role in limiting the number of groups that can participate in surface reactions with the iron centers. As discussed above, our model 


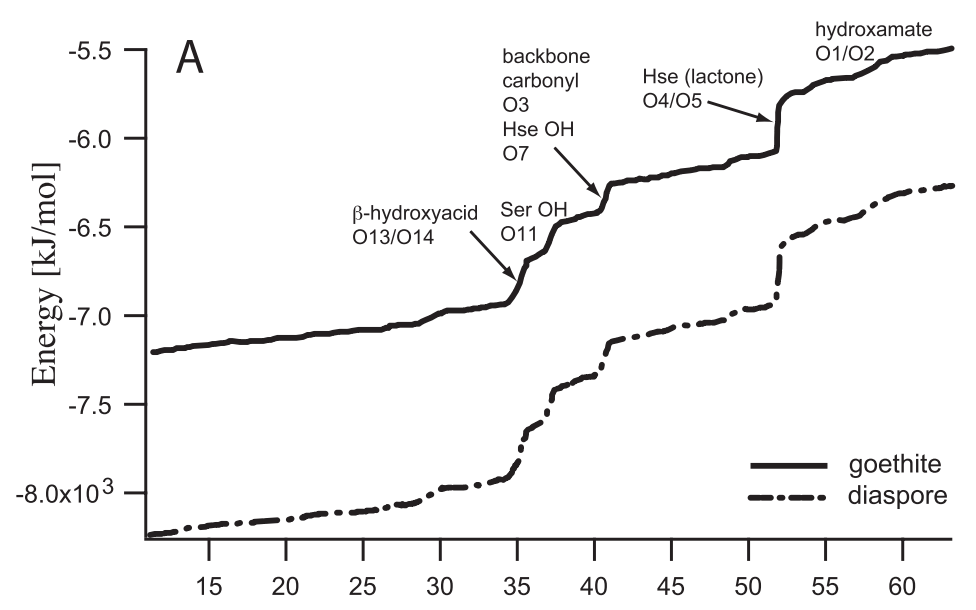

Au-mineral surface distance $[\AA]$

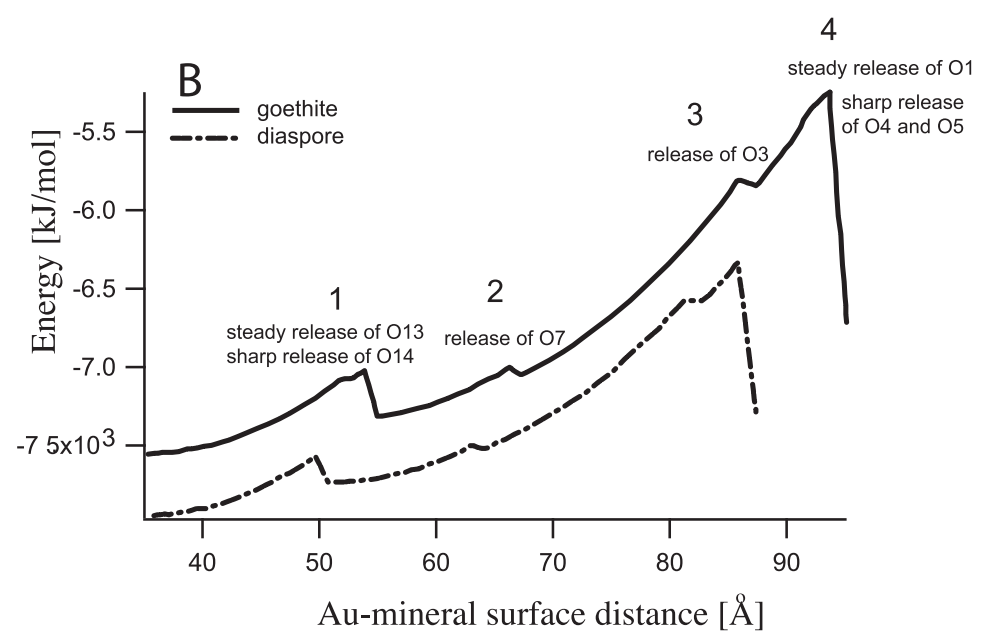

Fig. 15. (A) Simulated energy profile showing the successive attachment of azotobactin groups upon extension (approach) to the goethite and diaspore. Oxygen numbers (O1,O2,O4, etc.) refer to the numbering system shown in figure 12. (B) Simulated energy profile of siderophore retraction from goethite and diaspore (modified from Kendall and others, 2005. Reprinted from Chemical Geology, Modeling of azotobactin-goethite/diaspore interactions: Applications to molecular force measurements and siderophoremineral reactivity, p. 17-35, with permission from Elsevier.).

also suggests that many of these factors are indeed relevant when considering the interaction of azotobactin with the surface.

Significant gains in energy are calculated upon the coordination of each azotobactin group (fig. 14) with relatively large changes associated with the attachment of the hydroxyacid and the C-terminal Hse (lactone) (O4/O5). Relatively smaller gains in energy are associated with protonated groups attaching to the surface (for example, O7), suggesting a weaker, hydrogen bond component may be important in these interactions. The final energy of the goethite system at a Au-surface separation of 10.8 $\AA$ is $-7547.4 \mathrm{~kJ} / \mathrm{mol}$, and the derivative of the energy profile with respect to distance showed a maximum force of $923 \mathrm{pN}$. This force peak, qualitatively equivalent to an experimental jump to contact force (for example, the force at which the AFM 
cantilever jumps into contact with the surface; see Kendall and Lower, 2004), is associated with the docking of the Hse lactone group in our model. It may be tenuous to compare these results directly to AFM data collected in solution; however, it is worth noting that the modeled force magnitude and distance at which this jump occurred $(\sim 52 \AA)$ compared favorably with averaged experimental AFM data values (at both $\mathrm{pH}$ 3.5 and $\mathrm{pH} 7)$ collected with relatively high spring constants $\left(\mathrm{k}_{\mathrm{s}}=0.123 \mathrm{~N} / \mathrm{m}\right)$. This was not the case with other data sets collected with softer (less stiff) cantilevers $\left(\mathrm{k}_{\mathrm{s}} \approx 0.06 \mathrm{~N} / \mathrm{m}\right)$ that were perhaps less adept at capturing the steep gradient generated by the Hse lactone jump in the energy profile (Cappella and Dietler, 1999; Kendall and Lower, 2004). Here the lower spring constant resulted in a longer jump to contact distance because the onset of the jump was already able to bend the cantilever.

Other factors should be considered when making this semi-quantitative comparison of modeled forces with AFM data. The simulated value is representative of a single azotobactin molecule interacting with the surface. Based on dimensional considerations and a Johnson-Kendall-Roberts model of adhesion, the capture of a single molecule interaction was not predicted for the prior AFM experiments (Kendall and Hochella, 2003). Also, the simulation was completed in a vacuum and the jump to contact energies and distances are expected to be lower in the presence of water due to charge shielding. An assessment of the additive effect of multiple interactions (or a reassessment of the number of interactions captured in the AFM data), together with a characterization of the influence of a solvated environment may help to simulate the AFM experiments more closely. The difference between such an approach and the current study would provide more information on solvation and hydrogen bonding interactions.

\section{Simulated Azotobactin - Free $\mathrm{Fe}^{3+}$ Interaction}

The bonding sequence during extension towards the goethite surface is different from the bonding order associated with the interaction of the azotobactin-linker construct with a single ferric iron atom. This emphasizes the different roles that each functional group may play depending if the siderophore encounters an Fe atom in a solid or aqueous form. As the free ferric iron is moved into the siderophore structure parallel to its extended peptide backbone axis, the following attachment and release sequence is revealed ( $\mathrm{O}$ atoms separated by commas indicate two discrete events): $\mathrm{O} 1$ attach, $\mathrm{O} 2$ attach, O4/O5 attach, O7 attach, O5 release, O8/O9 attach, O4 release. Again, the hydroxamate $(\mathrm{O} 1, \mathrm{O} 2)$ is shown to participate in the coordination. However, steric hindrances preclude attachment of the catechol and the $\beta$-hydroxyacid groups (O13/O14), even though the ferric iron was advanced to a separation of 8 $\AA$ from the gold atom. The expected hexadentate (hydroxamate, catechol, hydroxyacid) coordination that is suggested for the stable azotobactin (Azb) - Fe(III) ${ }_{\mathrm{aq}} \mathrm{com}$ plex is not observed, probably as a result of the direction and geometry of the advance of the iron into the structure and the reduction in the degrees of conformational freedom imposed by the linkage. Note that this protocol was employed to facilitate comparison with experimental and simulated force experiments. The presence of the available uncoordinated chelating groups in the model containing free iron are, however, in agreement with the experimental AFM data on the azotobactin-goethite interaction in Fe-rich solutions. During AFM experiments, the azotobactin-goethite interaction was probed after successively adding soluble free $\mathrm{Fe}^{3+}$ ion (Kendall and Hochella, 2003). A sharp decrease in adhesion forces with increasing [Fe(III) $)_{\mathrm{aq}}$ ] was followed by a plateau of residual adhesion that existed in spite of sufficient iron to satisfy the chelating groups associated with all of the azotobactin molecules attached to the tip, cantilever and substrate (Kendall and Hochella, 2003). The source of the residual adhesion was hypothesized to be free chelating groups or other sidechain or 


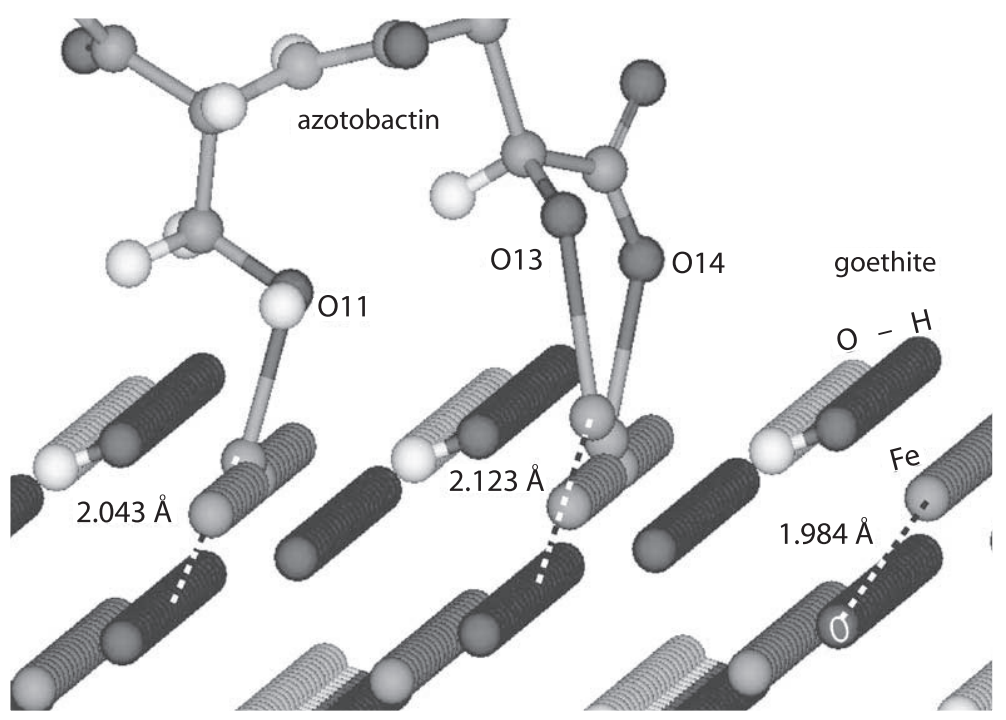

Fig. 16. Displacement of irons from their equilibrium position in the lattice $\left(\mathrm{Fe}-\mathrm{O}_{\text {goethite }}\right.$ bond distance $=1.984 \AA$ ) by the $\beta$-hydroxycarboxylic acid $(\mathrm{O} 13$ and $\mathrm{O} 14)$ and the O11 Ser groups. Lines connecting the siderophore oxygens and the goethite iron represent the Morse potentials used to model the siderophore-metal interaction. The figure shows an intermediate stage of retraction with distance between the respective $\mathrm{O}$ atoms $(\mathrm{O} 11, \mathrm{O} 13$, and $\mathrm{O} 14)$ and the surface $\mathrm{Fe}$ atoms of 2.2 to $2.3 \AA$. Once this distance is $>$ $2.5 \AA$, the Fe atom snaps back into the surface in vacuum conditions (modified from Kendall and others, 2005. Reprinted from Chemical Geology, Modeling of azotobactin-goethite/diaspore interactions: Applications to molecular force measurements and siderophore-mineral reactivity, p. 17-35, with permission from Elsevier.).

backbone $\mathrm{O}$ atoms interacting with the surface; an idea that is now supported by the conformation suggested in the azotobactin-Fe(III) model.

\section{Simulated Retraction Force Trace - Azotobactin and Goethite/Diaspore}

Prior to retracting the azotobactin from the surface, the metals in each mineral lattice in close association $(<2.2 \AA$ away) with siderophore $\mathrm{O}$ atoms were identified $(8$ total for goethite and diaspore) and marked with distance monitors (these distance monitors have no direct influence on the calculations; rather they help to describe the metal $\mathrm{mineral}_{\text {- }} \mathrm{O}_{\text {siderophore }}$ interaction). These metal atoms were allowed to relax and a Morse potential was defined between the metal and the coordinating siderophore $\mathrm{O}$ atom. Because no additional short-range interaction of siderophore groups was observed at Au-surface separation distances of less than $\approx 36 \AA$ during approach, simulation time was reduced by beginning the retractions at this point. Metals are removed from both minerals by the siderophore in the simulated retraction.

Goethite.-During retraction from the goethite, one Fe atom is completely removed from the structure by the terminal Hse group (O4/O5) and 4 others are displaced significantly from their equilibrium position on the surface (for example,

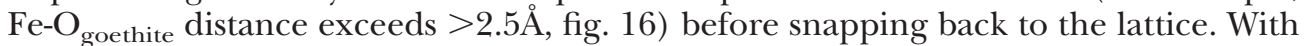
the exception of a sharp increase followed by a sharp decrease in the Fe atom displacement associated with $\beta$ hydroxyacid O14, the displacement magnitudes steadily increase as the overall accumulated stress is transferred from one functional group to the next (data not shown). This trend parallels the energy profile, which is characterized by a large initial buildup, followed by a steady rise in energy with periodic spikes correlating to the release of specific functional groups (some with a metal attached, fig. 
15B). As expected, the order of release from the surface is close to the reverse of the extension attachment sequence, with differences in the order of release of the C-terminal groups. The release sequence is as follows: $\mathrm{O} 13, \mathrm{O} 14, \mathrm{O} 11, \mathrm{O} 7 / \mathrm{O} 3, \mathrm{O} 2, \mathrm{O} 1$, O4/O5. Interestingly, the Hse $\mathrm{OH}(\mathrm{O} 7)$ and a component of a backbone carbonyl (O3) are coupled in their release, in spite of a separation of almost a nanometer in contour length (for example, the maximum end-to-end distance of the extended, linearized azotobactin molecule). Conversely, a lack of coupling is observed between the hydroxamate and hydroxyacid oxygen pairs separated by 1 to $2 \AA$.

Diaspore.-The shape of the diaspore retraction energy profile is similar to that of goethite, in that it shows four major energy peaks associated with the eight coordinations (fig. 15B). However, closer inspection of the $\mathrm{Al}$ displacements and the separation distances at which siderophore functional groups release from the surface reveals a significantly different interaction. One $\mathrm{Al}$ atom is removed from the structure (again by the terminal Hse group), and only 1 other atom is significantly displaced during retraction of azotobactin from the diaspore surface. The large metal displacement observed for the Fe-hydroxyacid coordination is much less pronounced with the diaspore and, overall, a two-fold increase in the average net maximum metal displacement is observed for goethite versus diaspore. The sequence is essentially the same as that of goethite, however, functional groups release from the diaspore surface at smaller separation distances. This is reflected in the energy profile where shifts in diaspore peak positions (to the left) show lower energy accumulation in the $\mathrm{Al}-\mathrm{O}_{\text {siderophore }}$ surface bond prior to release compared to the $\mathrm{Fe}-\mathrm{O}_{\text {siderophore }}$ bond. In other words, the Fe-O(siderophore) bonds persist into a higher force regime resulting in relative goethite adhesion values that are 1.5 to 1.7 times higher than for diaspore, in spite of the more negative pullout energy predicted for $\mathrm{Al}$ over $\mathrm{Fe}$. In the absence of the siderophore, the higher forces appear to result from the $\mathrm{Fe}-\mathrm{O}_{\text {siderophore }}$ linkage and not the Fe- $\mathrm{O}_{\text {goethite }}$ bond. This relationship is comparable to AFM goethite/diaspore adhesion ratios (2 - 3 times), which also show increased adhesion and affinity for goethite (Kendall and Hochella, 2003). Note that the more negative overall energy values associated with the diaspore are likely due to the differential stress imposed on the azotobactin molecule by subtle differences in the metal spacing on the diaspore (010) surface and by the higher lattice energy of diaspore with respect to goethite. The latter effect lowers the absolute energy due to stronger metal-mineral interactions within diaspore.

The combination of quantum mechanical and empirical force-field simulations show that even though only two functional groups at a time can chelate a metal atom at the surface (in contrast to six as in the case of siderophore-metal complexation in solution), it is possible that despite the steric hindrance, $\mathrm{Fe}^{3+}$ ions can be removed from the goethite surface (Kendall and others, 2005).

$$
\text { Siderophore Affinity for } \mathrm{Fe}^{3+} \text { over } \mathrm{Al}^{3+}
$$

The specificity and increased affinity of azotobactin for the Fe atom in goethite over $\mathrm{Al}$ in diaspore that is evident in force measurements and in the molecular mechanics simulations (for example, increased energy changes upon retraction) is corroborated by the binding energies calculated from first principles. With both siderophore analogs, the acetohydroxamic acid and the hydroxycarboxylic acid, binding energies are more negative for $\mathrm{Fe}^{3+}$ compared to $\mathrm{Al}^{3+}$. The absolute ab initio values show the same relationship as energies calculated from experimentally derived formation constants $\left(\mathrm{K}_{\mathrm{f}}\right)$; however, the latter values are higher (less negative). This is, in part, because the $a b$ initio calculations do not include an entropy component, which would drive the energies down to a less negative value.

Based on previous observations (Hider, 1984; Albrecht-Gary and Crumbliss, 1998; Kendall and Hochella, 2003), it was hypothesized that part of the observed specificity 
and increased affinity of azotobactin for Fe atoms was a result of iron's increased electronegativity over Al. Relative comparison of the optimized Mulliken charge distributions from the Gaussian98 models of the $\mathrm{Fe}$ and $\mathrm{Al}$ ligand complexes supports this argument. The larger ionic radius of $\mathrm{Fe}$ and an electronegativity closer to that of oxygen results in an $\mathrm{Fe}$ atom with lower positive charge associated with less negative $\mathrm{O}$ atoms. In other words, the $\mathrm{Fe}_{\text {goethite }}-\mathrm{O}_{\text {siderophore }}$ bond has a more covalent character than the $\mathrm{Al}_{\text {diaspore }}-\mathrm{O}_{\text {siderophore }}$ bond. Comparison of the hydration energies associated with the $\mathrm{Fe}^{3+}$ and $\mathrm{Al}^{3+}$ ions coupled with observations made during the ab initio runs present the possibility of surface hydration energies playing a role in the siderophore mineral interaction forces observed with the AFM. While these values have not been measured for goethite and diaspore, it is possible that the increased (more negative) hydration energy associated with the $\mathrm{Al}^{3+}$ ion (versus $\mathrm{Fe}^{3+}$ ) could correlate with an increased surface hydration energy for diaspore over goethite. Therefore, the lowered siderophore affinity observed for the diaspore surface could also reflect the extra energy required to remove water from the diaspore surface.

\section{ADSORPTION OF OLIGOMERS TO STEP EDGES AS A PRECURSOR OF BIOMINERALIZATION}

In the last two sections, we described interactions between organic molecules and mineral surfaces, where the structural matching or steric considerations are only important at the scale of 1 to 3 bond distances. In contrast, structural matching at inorganic-organic interfaces along at least nanometers of interface is a key concept in oriented nucleation in biomineralization. As a precursor of biomineralization, we are studying the interaction of oligomers/polypeptide chains on (1014) calcite surface. The lowest energy faces of pure calcite are the (10 $\overline{1} 4)$ family of faces. Our main objective is to find suitable orientation of amino-acid residues in these peptide chains, where these peptide chains align themselves parallel to the calcite surface. The stereochemical relation between the coordination environment of ions in specific crystal faces $\left(\mathrm{Ca}^{2+}, \mathrm{CO}_{3}{ }^{2-}\right.$ in this case) and the arrangement of ligands (that is peptide residues, oligomers) around ions bound to the surface is a potential factor for organic nucleation and selectivity of biominerals. If the distance between the repeating residue units in the adsorbent matches the distance between the repeating units in the adsorbate surface, the adsorbent long chain polymer or oligomeric organic compound can lie parallel to the surface step. To start with, we have performed calculations of various sequences of small chain peptide residues along non-polar (periodic bond chains of alternating $\mathrm{Ca}^{2+}$ and $\mathrm{CO}_{3}{ }^{2-}$ ions with no dipole moment perpendicular to the step) and on polar surface steps (steps bounded by either $\mathrm{Ca}^{2+}$ or $\mathrm{CO}_{3}{ }^{2-}$ ions). Each peptide residue was composed of 3 amino acids. The maximum adsorption energy that we found was for (phe-leu-lys) ${ }^{4}$, where the total adsorption energy to a non-polar calcite surface step is $-1.071 \mathrm{eV}$ [average of $-0.357 \mathrm{eV} /$ (amino acid unit), negative values $=$ adsorption; positive $=$ repulsion $]$. Adsorption energy values for other peptide chains vary between $-0.1879 \mathrm{eV} /$ (amino acid) to $-0.2890 \mathrm{eV} /$ (amino acid).

Almost parallel alignment of these 3-amino acid peptide residues is observed when aligned with polar $\mathrm{Ca}^{2+}$-bounded surface steps where the dominant interaction between the negatively charged peptide backbone and $\mathrm{Ca}^{2+}$ along the surface step is of electrostatic nature. Adsorption energy values in this case range between -0.1733 $\mathrm{eV} /($ amino acid) to $-0.2602 \mathrm{eV} /$ (amino acid). The most energetically favorable adsorption is obtained for the sequence (phe-leu-lys) ${ }^{4-}$ with $-0.2978 \mathrm{eV} /$ amino acid.

Using the same concept, we have used longer peptide chains having 12 amino acids. Sequencing of amino acids has been obtained from encoded GPA, a calcium binding protein in the coccolithophorid Emiliania Huxleyi (Corstjens and others, 1998). Interaction of this 12-amino acid long peptide chain in both acidic (protonated) and alkaline (deprotonated) conditions with polar calcite steps for both cases $\left(\mathrm{Ca}^{2+}\right.$ and $\mathrm{CO}_{3}{ }^{-}$bounding) has been studied. At alkaline conditions, the adsorption 


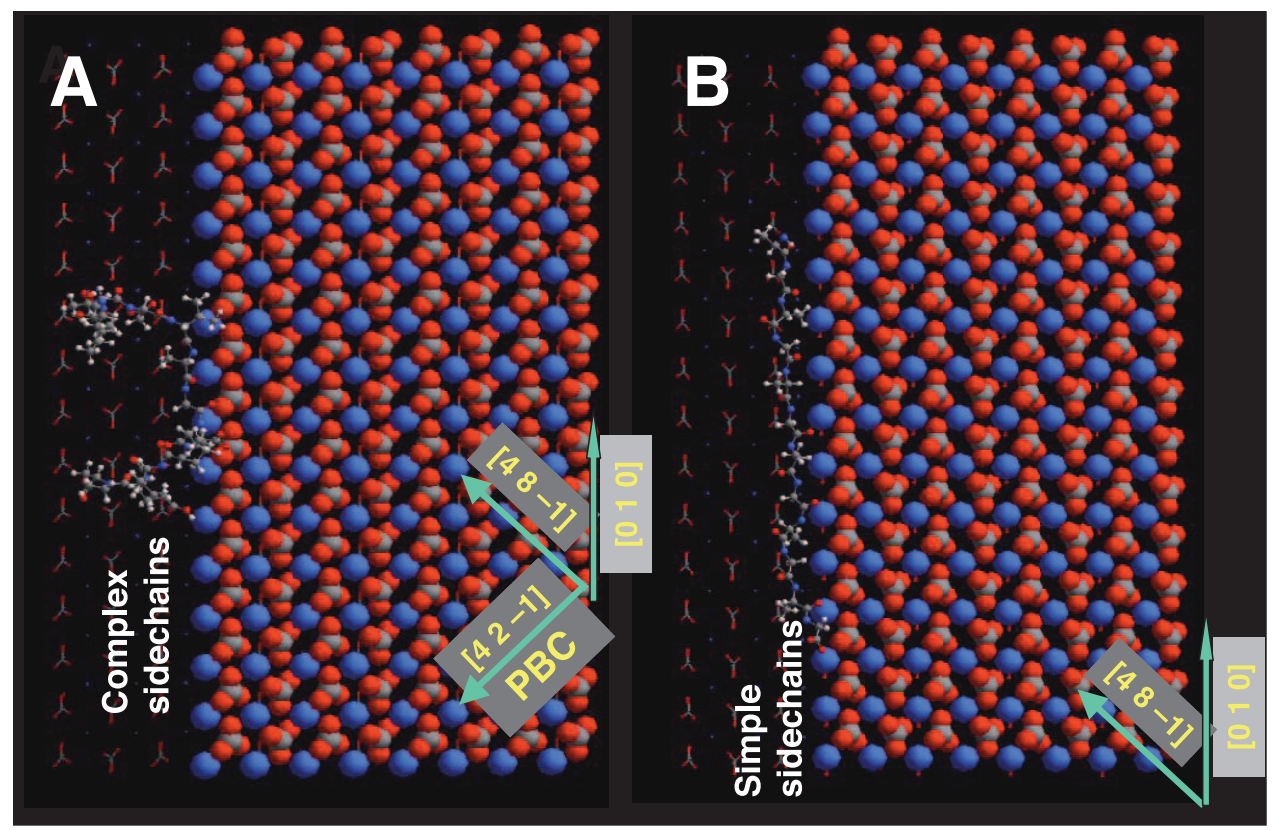

Fig. 17. (A) 12 amino-acid residue long peptide chain along a polar step on a calcite (10 $\overline{1} 4)$ surface: $\mathrm{Ca}^{2+}$ at step edge, total charge of the peptide chain is -13 (alkaline environment). (B) 12 amino-acid (alternating glycine and alanine) residue long peptide chain on polar, $\mathrm{CO}_{3}{ }^{-}$-bounded step edge, peptide is neutral (acidic environment).

energy of the negatively charged peptide with the $\mathrm{Ca}^{2+}$-bounded step edge is -0.09824 $\mathrm{eV} /$ amino acid. When the peptide residue is neutral (acidic condition), the adsorption energy is $-0.1978 \mathrm{eV} /$ amino acid residue $\left(\mathrm{CO}_{3}{ }^{2-}\right.$ at step edge). In this long chain peptide, amino acid residues at the middle part of the chain are closer to the surface than the end-members giving a $U$ shape to the peptide chain (fig. 17A). Better parallel alignment of the peptide chain to the calcite surface is observed in the neutral peptide than for the -13 charged peptide residue. This can be owed to the fact that in the negatively charged long chain peptide, electrostatic interactions between charged side chains of the amino acids and the peptide backbone coupled with steric hindrance of large side chain prevents parallel alignment. It is also known that proteins can inhibit calcite growth and that ability is attributed to backbone flexibility of peptide chain (Gerbaud and others, 2000), which may be another reason why we see flexible, not parallel, peptide chains on these polar steps.

Our simulations show that the presence of large side chains in the amino acid residues can cause steric hindrance and prevent the peptide chain from aligning parallel to the calcite surface. In the 12-amino acid peptide residue, the presence of a 5-member heterocyclic ring in proline, $\mathrm{CH}\left(\mathrm{CH}_{3}\right)-\mathrm{CH}_{2}-\mathrm{CH}_{3}$ in isoleucine, and $\mathrm{CH}_{2}-\mathrm{CH}_{2}-$ $\mathrm{COOH}$ in glutamic acid are responsible for the steric hindrance causing the $\mathrm{U}$ shape of the peptide chain (fig. 17A). To minimize this steric hindrance, the large side chains in amino acid residues have been replaced by $\mathrm{H}-$ and $\mathrm{CH}_{3}{ }^{-}$groups, thus constructing a 12-residue peptide chain with alternating glycine and alanine amino acids. At low $\mathrm{pH}$, this 12-amino acid long glycine-alanine peptide residue aligns itself more or less parallel to the calcite step edge, verifying that large side chains in amino acids are major obstacles in parallel alignment (fig. 17B). The adsorption energy for this gly-ala 
peptide residue is $-0.0428 \mathrm{eV} /$ amino acid residue along the polar $\mathrm{CO}_{3}{ }^{2-}$ step. The average distance between the amino acid residues in this peptide chain is $3.185 \AA$.

SUMMARY AND CONCLUSIONS

\section{The Influence of Monovalent Ions on the Growth/Dissolution Kinetics and Morphology of Divalent Crystals}

Before the interaction of more complex organic molecules with mineral surfaces can be understood, the interaction of monovalent ions in solution on the kinetics and morphology of growth and dissolution of divalent crystals has been evaluated. This is important in order to avoid to attribute changes in surface morphologies, and growth and dissolution kinetics, to the potential influence of organic molecules in solution.

Monovalent ions tend to stabilize previously polar steps on the surfaces of divalent crystals. Consequently, the morphologies of microscopic surface features such as growth islands and spirals, and etch pits are changed, ultimately influencing crystal habits.

Monovalent ions can increase both growth and dissolution rates by modifying the rate-controlling steps of growth and dissolution. For growth, this is the initialization of a new growth row. For dissolution, this is the formation of a kink site along the edge of an etch pit.

The latter point is another example that growth and dissolution are not necessarily reverse processes of each other.

\section{Growth-Inhibitor-Sulfate Interactions}

Direct AFM measurements of growth rates of barite steps in the presence of different concentrations of inhibitors allowed us to construct adsorption isotherms indicating a Langmuir-type of behavior for all inhibitors used. A linear relationship exists between $v_{0} /\left(v_{0}-v_{i}\right)$ and $[I n h]^{-1}$ for inhibitor concentrations lower than $10 \mu \mathrm{mol} / 1$. Since such isotherms have been constructed from growth rates measured in situ on monomolecular barite steps, they represent a direct demonstration of the molecular basis of the Langmuir model for adsorption processes. Slopes of the adsorption isotherms were calculated from AFM experiments. Their values are similar to values obtained conducting classical bulk experiments. This demonstrates that AFM can be used to obtain quantitative adsorption data.

Calculations conducted using molecular modeling methods showed that the five studied phosphonates are only effective as growth inhibitors by blocking kink sites along monomolecular steps. Adsorption positions on terraces cannot be considered as possible inhibition sites due to their positive adsorption energies. This is in agreement with AFM observations and measurements. Calculated adsorption energies of the five phosphonates on kink sites are in the order of hundreds of $\mathrm{kJ} / \mathrm{mol}$, indicating chemisorption.

From both the growth rate versus inhibitor concentration data and the calculated slope of the adsorption isotherms (that is, affinity constant), we can give the following ranking of inhibitor effectiveness: PBTC $>$ NTMP $>$ MDP $>$ HEDP $>>$ AMP. This ranking of inhibiting effectiveness is consistent with previous experimental works.

\section{Siderophore-Oxide Interactions}

Molecular and quantum mechanical calculations are effective in providing qualitative and quantitative information on the azotobactin-metal oxide interaction that is captured during force measurements on the same system. Computer simulations of the AFM extension force traces show that both backbone and sidechain azotobactin oxygens have the opportunity to interact with the diaspore and goethite mineral surfaces; however, steric considerations and constraints imposed by the presence of the 
mineral lattice dictate which ones ultimately coordinate. Similar functional groups are associated with each mineral surface after extension; however, upon retraction of the molecule from these surfaces, the energy profiles of these pull-off events for diaspore and goethite are distinct. Quantum mechanical calculations of $\mathrm{Fe}^{3+} / \mathrm{Al}^{3+}$ chelates including hydration energies provide evidence that the ligand-surface interaction energetically favors the iron oxide. Metal removal is predicted in the models completed in vacuum; and additional simulations, ones that employ a bidentate, mononuclear coordination (as opposed to a bidentate, binuclear coordination) or include water to act as a helper ligand confirm that siderophore metal removal via direct surface contact is possible in a natural system. In spite of the observed surface affinity, the ability of azotobactin to compete with smaller organic ligands (for example, oxalate) for sorption sites on the mineral remains to be determined. Future work could include sorption experiments coupled with force measurements to determine the effect of smaller ligands on azotobactin surface affinity and adhesion.

Steric hindrances limit the number of oxygens that coordinate with the surface to eight; however, for siderophore-oxide interactions in a natural system without the linkage to the AFM tip imposing limitations on molecular conformation, this number is expected to be higher. Azotobactin adsorption geometry is initially binuclear, but increased surface coordination (for example, a higher $\mathrm{O}_{\text {siderophore }}$ :Fe ratio associated with the surface complex) is likely upon displacement of the metal by the ligand or with changes in surface microtopography. One example of the latter is an increased coordination that results from siderophore oxygens accessing undercoordinated metals in surface sites associated with step edges. In both cases, increases in coordination result in a more stable configuration and stronger $\mathrm{Fe}-\mathrm{O}_{\text {siderophore }}$ bond.

Upon release from the surface (that is, due to thermal motion), the $\mathrm{Fe}-\mathrm{O}_{\text {siderophore }}$ bond (s) persist, allowing metal removal from the lattice. The energetics of the system is then minimized as the ligand reconfigures to enclose the iron in a multidentate coordination, and the defect site in the mineral lattice relaxes and becomes hydrated. A similar dissolution pathway is predicted for the diaspore; however, azotobactin specificity for the iron oxide surface over the aluminum oxide surface is observed in this study and in the AFM measurements (Kendall and Hochella, 2003). With both minerals present, this suggests the pathway will favor the iron oxide surface and will allow efficient azotobactin-mediated Fe(III) acquisition directly from the solid iron form.

\section{Polypeptide-Calcite Interactions}

Even though we are still beginning to evaluate the plethora of possibilities to let polypeptide chains interact with specific steps on calcite surfaces, we are starting to understand certain principles, for example steric hindrances caused by "bulky" sidechains. Future work will be directed to use adsorption energy calculations in a genetics-like way to find optimized polypeptide sequences for specific calcite (or other biomineral) faces and step directions.

\section{ACKNOWLEDGMENTS}

The authors would like to thank two anonymous reviewers for their helpful and constructive comments and the National Science Foundation (EAR-0403732) for financial support.

\section{REFERENCES}

Albrecht-Gary, A. M., and Crumbliss, A. L., 1998, Coordination chemistry of siderophores: Thermodynamics and kinetics of iron chelation and release, in Siegel, A., and Sigel, H., editors, Metal Ions in Biological Systems: Iron Transport and Storage in Microorganisms, Plants and Animals, v. 35: New York, Marcel Dekker, p. 239-327. 
Allan, N. L., Rohl, A. L., Gay, D. H., Catlow, C. R. A., Davey, R. J., and Mackrodt, W. C., 1993, Calculated bulk and surface properties of sulfates: Faraday Discussions, v. 95, p. 273-280.

Amjad, Z., editor, 1995, Mineral Scale Formation and Inhibition: New York, Plenum Press, 354 p.

Archibald, D. D., Gaber, B. P., Hopwood, J. D., Mann, S., and Boland, T., 1997, Atomic force microscopy of synthetic barite microcrystals: Journal of Crystal Growth, v. 172, p. 231-248.

Becke, A. D., 1993, Density-functional thermochemistry. III. The role of exact exchange: Journal of Chemical Physics, v. 98, p. 5648-5652.

Becker, U., and Gasharova, B., 2001, AFM observations and simulations of jarosite growth at the molecular scale: probing the basis for the incorporation of foreign ions into jarosite as a storage mineral: Physics and Chemistry of Minerals, v. 28, p. 545-556.

Becker, U., Bosbach, D., and Pina, C., 1998, Dynamic simulation of crystal growth at the molecular scale: Toronto, Canada, International Mineralogical Association, 17th General Meeting, p. A92.

Becker, U., Risthaus, P., Bosbach, D., and Putnis, A., 2002, Selective attachment of monovalent background electrolyte ions and growth inhibitors to polar steps on sulfates as studied by molecular simulations and AFM observations: Molecular Simulation, v. 28, p. 607-632.

Black, S. N., Bromley, L. A., Cottier, D., Davey, R. J., Dobbs, B., and Rout, J. E., 1991, Interactions at the organic inorganic interface - Binding motifs for phosphonates at the surface of barite crystals: Journal of the Chemical Society-Faraday Transactions, v. 87, p. 3409-3414.

Blount, C. W., 1977, Barite solubilities and thermodynamic quantities up to $300^{\circ} \mathrm{C}$ and 1400 bars: American Mineralogist, v. 62, p. 942-957.

Bosbach, D., 2002, Linking molecular scale barite precipitation mechanisms with macroscopic reaction rates, in Hellmann, R., and Wood, S. A., editors, Water-Rock Interactions, Ore Deposits, and Environmental Geochemistry: A Tribute to David A. Crerar: St. Louis, The Geochemical Society, Special Publication No. 7, p. 97-110.

Bosbach, D., and Hochella, M. F., Jr., 1996, Gypsum growth in the presence of growth inhibitors: A scanning force microscopy study: Chemical Geology, v. 132, p. 227-236.

Bosbach, D., Hall, C., and Putnis, A., 1998, Mineral precipitation and dissolution in aqueous solution: in situ microscopic observations on barite (001) with atomic force microscopy: Chemical Geology, v. 151, p. 143-160.

Bosbach, D., Coveney, P. V., Griffin, J. L. W., Putnis, A., Risthaus, P., Stackhouse, S., and Whiting, A., 2002, The rational design, synthesis and demonstration of the recognition and binding of a diaza-dioxa-12crown-4 diphosphonate macrocycle to all crystal growth faces of barium sulfate: Journal of the Chemical Society, Perkin Transactions 2, p. 1238-1245.

Brixner, L. H., 1967, Segregation coefficients of rare earth niobates in $\mathrm{CaMoO}_{4}$ : Journal of the Electrochemical Society, v. 114, p. 108-109.

Busenberg, E., Plummer, L. N., and Parker, V. B., 1984, The solubility of strontianite $\left(\mathrm{SrCO}_{3}\right)$ in $\mathrm{CO}_{2}-\mathrm{H}_{2} \mathrm{O}$ solutions between 2 and $91^{\circ} \mathrm{C}$, the association constants of $\mathrm{SrHCO}_{3}{ }^{+}(\mathrm{aq})$ and $\mathrm{SrCO}_{3}{ }^{\mathrm{O}}(\mathrm{aq})$ between 5 and $80^{\circ} \mathrm{C}$, and an evaluation of the thermodynamic properties of $\mathrm{Sr}^{2+}(\mathrm{aq})$ and $\mathrm{SrCO}_{3}(\mathrm{cr})$ at $25^{\circ} \mathrm{C}$ and 1 atm total pressure: Geochimica et Cosmochimica Acta, v. 48, p. 2021-2035.

Busing, W. R., and Levy, H. A., 1958, A single crystal neutron diffraction study of diaspore, $\mathrm{AlO}(\mathrm{OH})$ : Acta Crystallographica, v. 11, p. 798-803.

Cabrera, N., 1953, Macroscopic spirals and the dislocation theory of crystal growth: Journal of Chemical Physics, v. 21, p. 1111-1112.

Cabrera, N., and Vermilyea, D. A., 1958, The growth of crystals from solution, in Doremus, R. H., Roberts, B. W., and Turnbull, D., editors, Growth and Perfection of Crystals: London, Chapman and Hall, p. 393-410.

Cappella, B., and Dietler, G., 1999, Force-distance curves by atomic force microscopy: Surface Science Reports, v. 34, p. 1-2.

Cheah, S. F., Kraemer, S. M., Cervini-Silva, J., and Sposito, G., 2003, Steady-state dissolution kinetics of goethite in the presence of desferrioxamine B and oxalate ligands: implications for the microbial acquisition of iron: Chemical Geology, v. 198, p. 63-75.

Christy, A. G., and Putnis, A., 1993, The kinetics of barite dissolution and precipitation in water and sodium-chloride brines at $44-85^{\circ} \mathrm{C}$ : Geochimica et Cosmochimica Acta, v. 57, p. 2161-2168.

Cocozza, C., Tsao, C. C. G., Cheah, S. F., Kraemer, S. M., Raymond, K. N., Miano, T. M., and Sposito, G., 2002, Temperature dependence of goethite dissolution promoted by trihydroxamate siderophores: Geochimica et Cosmochimica Acta, v. 66, p. 431-438.

Cooper, T. G., and De Leeuw, N. H., 2002, Adsorption of methanoic acid onto the low-index surfaces of calcite and aragonite: Molecular Simulation, v. 28, p. 539-556.

Cornell, R. M., and Schwertmann, U., 1996, The Iron Oxides: Structure, Properties, Reactions, Occurrence and Uses: Zürich, VCH Verlagsgesellschaft, 573 p.

Corstjens, P., van der Kooij, A., Linschooten, C., Brouwers, G. J., Westbroek, P., and de Vrind-de Jong, E. W., 1998, GPA, a calcium-binding protein in the coccolithophorid Emiliania Huxleyi (Prymnesiophyceae): Journal of Phycology, v. 34, p. 622-630.

Coveney, P. V., Davey, R. J., Griffin, J. L. W., and Whiting, A., 1998, Molecular design and testing of organophosphonates for inhibition of crystallisation of ettringite and cement hydration: Chemical Communications, v. 14, p. 1467-1468

Coveney, P. V., Davey, R., Griffin, J. L. W., He, Y., Hamlin, J. D., Stackhouse, S., and Whiting, A., 2000, A new design strategy for molecular recognition in heterogeneous systems: A universal crystal-face growth inhibitor for barium sulfate: Journal of the American Chemical Society, v. 122, p. 11557-11558.

Davey, R. J., Black, S. N., Bromley, L. A., Cottier, D., Dobbs, B., and Rout, J. E., 1991, Molecular design based on recognition at inorganic surfaces: Nature, v. 353, p. 549-550. 
De Leeuw, N. H., and Cooper, T. G., 2004, A computer modeling study of the inhibiting effect of organic adsorbates on calcite crystal growth: Crystal Growth and Design, v. 4, p. 123-133.

De Leeuw, N. H., and Parker, S. C., 1997, Atomistic simulation of the effect of molecular adsorption of water on the surface structure and energies of calcite surfaces: Journal of the Chemical Society-Faraday Transactions, v. 93, p. 467-475.

De Leeuw, N. H., Parker, S. C., and Harding, J. H., 1999, Molecular dynamics simulation of crystal dissolution from calcite steps: Physical Review B, v. 60, p. 13792-13799.

Dove, P. M., and Czank, C. A., 1995, Crystal-chemical controls on the dissolution kinetics of the isostructural sulfates - celestite, anglesite, and barite: Geochimica et Cosmochimica Acta, v. 59, p. 1907-1915.

Dunn, K., and Yen, T. F., 1999, Dissolution of barium sulfate scale deposits by chelating agents: Environmental Science and Technology, v. 33, p. 2821-2824.

Frisch, M. J., Tomasi, J., Pople, J., and Gaussian, I., 1998, Gaussian98: Pittsburgh, Pennsylvania.

Gale, J., 1998, GULP (General Utility Lattice Program): London, The Royal Institution.

Gerbaud, V., Pignol, D., Loret, E., Bertrand, J. A., Berland, Y., Fontecilla-Camps, J. C., Canselier, J. P., Gabas, N., and Verdier, J. M., 2000, Mechanism of calcite crystal growth inhibition by the N-terminal undecapeptide of lithostathine: Journal of Biological Chemistry, v. 275, p. 1057-1064.

Gualtieri, A. F., and Venturelli, P., 1999, In situ study of the goethite-hematite phase transformation by real time synchrotron powder diffraction: American Mineralogist, v. 84, p. 895-904.

Hansen, D. C., McCafferty, E., Lins, C. W., and Fitzpatrick, J. J., 1995, An FT-IR investigation of parabactin adsorbed onto aluminum: Applied Surface Science, v. 84, p. 85-90.

Hay, B. P., and Rustad, J. R., 1994, Structural criteria for the rational design of Selective Ligands - Extension of the MM3 force-field to aliphatic ether Complexes of the alkali and alkaline-Earth cations: Journal of the American Chemical Society, v. 116, p. 6316-6326.

Hay, B. P., Zhang, D. L., and Rustad, J. R., 1996, Structural criteria for the rational design of selective ligands. 2. Effect of alkyl substitution on metal ion complex stability with ligands bearing ethylene-bridged ether donors: Inorganic Chemistry, v. 35, p. 2650-2658.

Hay, B. P., Dixon, D. A., Vargas, R., Garza, J., and Raymond, K. N., 2001, Structural criteria for the rational design of selective ligands. 3. Quantitative structure-stability relationship for iron(III) complexation by tris-catecholamide siderophores: Inorganic Chemistry, v. 40, p. 3922-3935.

He, S. L., Oddo, J. E., and Tomson, M. B., 1995, The nucleation kinetics of barium-sulfate in NaCl solutions up to $6 \mathrm{M}$ and $90^{\circ} \mathrm{C}$ : Journal of Colloid and Interface Science, v. 174, p. 319-326.

Hersman, L., Lloyd, T., and Sposito, G., 1995, Siderophore-promoted dissolution of hematite: Geochimica et Cosmochimica Acta, v. 59, p. 3327-3330.

Hersman, L., Maurice, P., and Sposito, G., 1996, Iron acquisition from hydrous Fe(III)-oxides by an aerobic Pseudomonas sp: Chemical Geology, v. 132, p. 25-31.

Hider, R. C., 1984, Siderophore mediated adsorption of iron, in Clarke, M. J., Ibers, J. A., Mingos, D. M. P., Palmer, G. A., Sadler, P. J., and Williams, R. J. P., editors, Structure and Bonding: Siderophores from Microorganisms and Plants, v. 58: Heidelberg, Springer-Verlag, p. 25-87.

Higgins, S. R., Jordan, G., Eggleston, C. M., and Knauss, K. G., 1998, Dissolution kinetics of the barium sulfate (001) surface by hydrothermal atomic force microscopy: Langmuir, v. 14, p. 4967-4971.

Holmen, B. A., and Casey, W. H., 1996, Hydroxamate ligands, surface chemistry, and the mechanism of ligand-promoted dissolution of goethite $\alpha-\mathrm{FeOOH}(\mathrm{s})$ : Geochimica et Cosmochimica Acta, v. 60, p. $4403-4416$.

Holmen, B. A., Tejedor-Tejedor, M. I., and Casey, W. H., 1997, Hydroxamate complexes in solution and at the goethite-water interface: A cylindrical internal reflection Fourier transform infrared spectroscopy study: Langmuir, v. 13, p. 2197-2206.

Jones, F., Clegg, J., Oliveira, A., Rohl, A. L., Ogden, M. I., Parkinson, G. M., Fogg, A. M., and Reyhani, M. M., 2001, Anomalous behaviour within a systematic series of barium sulfate growth modifiers: CrystEngComm, v. 3(40), p. 165-167, DOI: 10.1039/b106729j.

Jones, F., Oliveira, A., Rohl, A. L., Parkinson, G. M., Ogden, M. I., and Reyhani, M. M., 2002, Investigation into the effect of phosphonate inhibitors on barium sulfate precipitation: Journal of Crystal Growth, v. 237 , p. $424-429$.

Kalinowski, B. E., Liermann, L. J., Brantley, S. L., Barnes, A., and Pantano, C. G., 2000, X-ray photoelectron evidence for bacteria-enhanced dissolution of hornblende: Geochimica et Cosmochimica Acta, v. 64, p. 1331-1343.

Kendall, T. A., and Hochella, M. F., Jr., 2003, Measurement and interpretation of molecular-level forces of interaction between the siderophore azotobactin and mineral surfaces: Geochimica et Cosmochimica Acta, v. 67, p. 3537-3546.

Kendall, T. A., and Lower, S. K., 2004, Forces between minerals and biological surfaces in aqueous solution: Advances in Agronomy, v. 82, p. 1-54.

Kendall, T. A., Hochella, M. F., Jr., and Becker, U., 2005, Computational modeling of azotobactin-goethite/ diaspore interactions: Applications to molecular force measurements and siderophore-mineral reactivity: Chemical Geology, v. 216, p. 17-35.

Kraemer, S. M., Cheah, S. F., Zapf, R., Xu, J. D., Raymond, K. N., and Sposito, G., 1999, Effect of hydroxamate siderophores on $\mathrm{Fe}$ release and $\mathrm{Pb}$ (II) adsorption by goethite: Geochimica et Cosmochimica Acta, v. 63, p. 3003-3008.

Lee, C. T., Yang, W. T., and Parr, R. G., 1988, Development of the Colle-Salvetti correlation-energy formula into a functional of the electron-density: Physical Review B, v. 37, p. 785-789.

Li, M., and Mann, S., 2000, Emergence of morphological complexity in $\mathrm{BaSO}_{4}$ fibers synthesized in AOT microemulsions: Langmuir, v. 16, p. 7088-7094.

Liermann, L. J., Kalinowski, B. E., Brantley, S. L., and Ferry, J. G., 2000, Role of bacterial siderophores in dissolution of hornblende: Geochimica et Cosmochimica Acta, v. 64, p. 587-602. 
Lumetta, G. J., Rapko, B. M., Garza, P. A., Hay, B. P., Gilbertson, R. D., Weakley, T. J. R., and Hutchison, J. E., 2002, Deliberate design of ligand architecture yields dramatic enhancement of metal ion affinity: Journal of the American Chemical Society, v. 124, p. 5644-5645.

Mann S., 2001, Biomineralization: Oxford, United Kingdom, Oxford University Press, 198 p.

McWhirter, M. J., Bremer, P. J., Lamont, I. L., and McQuillan, A. J., 2003, Siderophore-mediated covalent bonding to metal (oxide) surfaces during biofilm initiation by Pseudomonas aeruginosa bacteria: Langmuir, v. 19, p. 3575-3577.

Miertus, S., and Tomasi, J., 1982, Approximate evaluations of the electrostatic free-energy and internal energy changes in solution processes: Chemical Physics, v. 65, p. 239-245.

Monnin, C., and Galinier, C., 1988, The solubility of celestite and barite in electrolyte-solutions and natural waters at $25^{\circ} \mathrm{C}$ - a thermodynamic study: Chemical Geology, v. 71, p. 283-296.

Nielsen, A. E., and Sohnel, O., 1971, Interfacial tensions electrolyte crystal-aqueous solution, from nucleation data: Journal of Crystal Growth, v. 11, p. 233-234.

Nygren, M. A., Gay, D. H., Catlow, C. R. A., Wilson, M. P., and Rohl, A. L., 1998, Incorporation of growth-inhibiting diphosphates into steps on the calcite cleavage plane surface: Journal of the Chemical Society-Faraday Transactions, v. 94, p. 3685-3693.

Palanche, T., Marmolle, F., Abdallah, M. A., Shanzer, A., and Albrecht-Gary, A. M., 1999, Fluorescent siderophore-based chemosensors: iron(III) quantitative determinations: Journal of Biological Inorganic Chemistry, v. 4, p. 188-198.

Parker, S. C., Titiloye, J. O., and Watson, G. W., 1993, Molecular modeling of carbonate minerals - studies of growth and morphology: Philosophical Transactions of the Royal Society of London Series AMathematical Physical and Engineering Sciences, v. 344, p. 37-48.

Pina, C. M., Becker, U., Risthaus, P., Bosbach, D., and Putnis, A., 1998a, Molecular-scale mechanisms of crystal growth in barite: Nature, v. 395, p. 483-486.

Pina, C. M., Bosbach, D., Prieto, M., and Putnis, A., 1998b, Microtopography of the barite (0 01 1) face during growth, AFM observations and PBC theory: Journal of Crystal Growth, v. 187, p. 119-125.

Pina, C. M., Putnis, C. V., Becker, U., Biswas, S., Carroll, E. C., Bosbach, D., and Putnis, A., 2004, An atomic force microscopy and molecular simulations study of the inhibition of barite growth by phosphonates: Surface Science, v. 553, p. 61-74

Putnis, A., Putnis, C. V., and Paul, J. M., 1995, The efficiency of a DTPA-based solvent in the dissolution of barium sulfate scale deposits: San Antonio, Texas, Paper SPE 029094 Proceedings of the 1995 SPE International Symposium on Oilfield Chemistry, p. 773-785

Qi, L. M., Cölfen, H., and Antonietti, M., 2000, Control of barite morphology by double-hydrophilic block copolymers: Chemistry of Materials, v. 12, p. 2392-2403.

Rappe, A. K., Casewit, C. J., Colwell, K. S., Goddard, W. A., and Skiff, W. M., 1992, UFF, a full periodic-table force-field for molecular mechanics and molecular-dynamics simulations: Journal of the American Chemical Society, v. 114, p. 10024-10035.

Rashin, A. A., and Honig, B., 1985, Reevaluation of the Born model of ion hydration: Journal of Physical Chemistry, v. 89, p. 5588-5593.

Reardon, E. J., and Armstrong, D. K., 1987, Celestite $\left(\mathrm{SrSO}_{4}(\mathrm{~s})\right)$ solubility in water, seawater and $\mathrm{NaCl}$ solution: Geochimica et Cosmochimica Acta, v. 51, p. 63-72.

Redfern, S. E., and Parker, S. C., 1998, Atomistic simulation of the effects of calcium and strontium defects on the surface structure and stability of $\mathrm{BaSO}_{4}$ : Journal of the Chemical Society-Faraday Transactions, v. 94, p. 1947-1952.

Risthaus, P., Bosbach, D., Becker, U., and Putnis, A., 2001, Barite scale formation and dissolution at high ionic strength studied with atomic force microscopy: Colloids and Surfaces A-Physicochemical and Engineering Aspects, v. 191, p. 201-214.

Rohl, A. L., Gay, D. H., Davey, R. J., and Catlow, C. R. A., 1996, Interactions at the organic/inorganic interface: Molecular modeling of the interaction between diphosphonates and the surfaces of barite crystals: Journal of the American Chemical Society, v. 118, p. 642-648.

Sangwal, K., 1998, Growth kinetics and surface morphology of crystals grown from solutions: Recent observations and their interpretations: Progress in Crystal Growth and Characterization of Materials, v. 36, p. 163-248.

Sayle, D. C., Catlow, C. R. A., Harding, J. H., Healy, M. J. F., Maicaneanu, S. A., Parker, S. C., Slater, B., and Watson, G. W., 2000, Atomistic simulation methodologies for modelling the nucleation, growth and structure of interfaces: Journal of Materials Chemistry, v. 10, p. 1315-1324.

Shiraki, R., Rock, P. A., and Casey, W. H., 2000, Dissolution kinetics of calcite in $0.1 \mathrm{~m} \mathrm{NaCl} \mathrm{solution} \mathrm{at} \mathrm{room}$ temperature: An atomic force microscopic (AFM) study: Aquatic Geochemistry, v. 6, p. 87-108.

Telford, J. R., and Raymond, K. N., 1996, Siderophores: Comprehensive Supramolecular Chemistry, v. 1, p. 245-266.

Van der Leeden, M. C., and van Rosmalen, G. M., 1995, Adsorption behavior of polyelectrolytes on barium-sulfate crystals: Journal of Colloid and Interface Science, v. 171, p. 142-149.

Wang, K. S., Resch, R., Dunn, K., Shuler, P., Tang, Y. C., Koel, B. E., and Yen, T. F., 1999a, Dissolution of the barite (001) surface by the chelating agent DTPA as studied with non-contact atomic force microscopy: Colloids and Surfaces A-Physicochemical and Engineering Aspects, v. 160, p. 217-227.

Wang, K. S., Resch, R., Koel, B. E., Shuler, P. J., Tang, Y. C., Chen, H. J., and Yen, T. F., 1999b, Study of the dissolution of the barium sulfate (001) surface with hydrochloric acid by atomic force microscopy: Journal of Colloid and Interface Science, v. 219, p. 212-215.

Wang, K. S., Resch, R., Dunn, K., Shuler, P., Tang, Y. C., Koel, B. E., and Yen, T. F., 2000, Scanning force microscopy study of etch pits formed during dissolution of a barite (001) surface in CDTA and EDTA solutions: Langmuir, v. 16, p. 649-655. 